\title{
ECOLOGÍA Y ORGANIZACIÓN DEL TERRITORIO: EL CASO DE LA AGLOMERACIÓN URBANA DE MURCIA Y SU ÁREA DE INFLUENCIA. I: PROSPECCIÓN Y SECTORIZACIÓN TEMÁTICA
}

Por

P. Martín de Agar ${ }^{1}$; A. Torres Martínez ${ }^{1}$ y L. Ramírez-Díaz ${ }^{1}$

\author{
ECOLOGY AND LAND ARRANGEMENT: \\ THE CASE OF MURCIA AND SURROUNDINGS. \\ I: SURVERY AND LAND UNITS ESTABLISHMENT
}

\section{SUMMARY}

This report is the first part of an integrates ecological study on Murcia city and its surroundings. The phase of survey and land unit definition is described, based on those data obtained from the natural environment and the characterization of internally homogeneous sectors in relation to those elements that shape this area of study.

Nine thémes have been considered: Climate (5), Geology-Litology (15), Hidrology (8), Geomorphology (7), Soils (8), Vegetation (22), Fauna (6), Land uses (12) and Landscape (19). The figures refer to the numbers of characterized units.

The information obtained from each unit or sector is codified and stored getting data base up, easily useful in other works.

\section{RESUMEN}

Este trabajo constituye la primera parte de un estudio ecológico integrado sobre la agiomeración urbana de Murcia y su área de influencia. Se describe la fase de prospección y sectorización temática, basada en la obtención de datos sobre el medio ambiente natural y en la caracterización de sectores internamente homogéneos en relación con los elementos que configuran el área de estudio.

Se han considerado nueve temas: Clima (5), Geología-Litología (15), Hidrología (8), Geomorfología (7), Suelos (8), Vegetación (22), Fauna (6), Usos del Suelo (12) y Paisaje (19). Se expresa junto a cada tema el número de unidades caracterizadas.

La información obtenida para cada una de las unidades o áreas sectorizadas se codifica y almacena creándose una base de datos, fácilmente utilizable en otros estudios.

(1) Departamento de Zoologia. Facultad de Bilogia. Universidad de Murcia.

Los mapas que ilustran este trabajo se hallan encarpetados al final de este ejemplar. Sus fotolitos han sido cedidos amablemente por el Secretariado de Publicaciones de la.Universidad de Murcia. 


\section{INTRODUCCION}

En los úitimos años existe una creciente necesidad de utilizar un enfoque integrado en el estudio de los asentamientos humanos y de los problemas que se derivan de éstos. En este sentido, se requiere información acerca de los sistemas naturales, y ésta ha de estar organizada, analizada y asequible a fin de que sea aplicable a una gestión racional de los recursos y el medio ambiente.

Esta gestión racional ha de estar basada en el reconocimiento de los valores naturales del territorio como sistemas-recursos con una serie de actividades de uso o de explotación, y cuyos análisis lleva a dos aspectos que han de ser considerados en los proyectos de planeamiento territorial (EDINGTON y EDINGTON, 1977):

- En primer lugar, hay que tener en cuenta que cualquier actividad humana que se localice en un espacio concreto presenta unos requerimientos propios en relación con los factores o elementos naturales que encierra ese espacio.

- Por otra parte, una actividad localizada presenta distintos grados de compatibilidad con aquellas otras próximas a ésta, y viceversa.

Desde ambos puntos de vista se han de analizar e interpretar los ecosistemas del territorio, a fin de poder predecir la capacidad de respuesta de los recursos en cuestión.

El punto de partida en este análisis ha de ser la obtención de información ecológica suficiente sobre la respuesta de los ecosistemas, para poder comparar distintas alternativas de utilización del medio, considerando los impactos o «costes sociales» que cada una de ellas producirá en el caso de que se lleve a cabo.

El objetivo esencial de este trabajo es la aplicación a dos casos prácticos de la Región de Murcia, de un sistema de registro, evaluación y cartografia automática de impactos ambientales, a fin de comprobar la efectividad del método en estudios de planeamiento territorial. La aplicación de este sistema lleva consigo:

- Un reconocimiento integrado del territorio para determinar el estado ambiental en que se encuentra. 
- La búsqueda de indicadores ambientales que reflejen las condiciones actuales del territorio y su capacidad de uso. En este estudio se va a hacer especial hincapié en los factores climáticos y de vegetación como principales determinantes del estado actual y de la potencialidad de acogida de las dos zonas de estudio.

- La creación de un archivo de datos que sea manejable y ampliable en otros estudios, $y$

- La consideración de aspectos temáticos que, por su interés y grado de complejidad, requieran un análisis más detallado.

Dado el contenido y extensión del estudio realizado, se ha creído conveniente dividirlo en tres apartados que coinciden con otras tantas publicaciones: las dos primeras corresponden a la aglomeración urbana de Murcia y su área de influencia, y la última al Mar Menor y ecosistemas adyacentes.

En este trabajo, se expone la metodología seguida en la prospección y sectorización del primer caso de estudio, y los resultados obtenidos en dicha fase.

La siguiente publicación (MARTIN DE AGAR et al., en preparación) corresponde a las fases de diagnosis y evaluación de impactos, llevada a cabo en la misma zona anteriormente señalada. El tercer trabajo (MARTIN DE AGAR et al., en preparación) recoge otro caso práctico realizado en el área del Mar Menor y ecosistemas adyacentes, en donde se aplicó la misma metodología con algunas modificaciones referentes a las modalidades de uso del suelo.

\section{MATERIAL Y METODOS}

\section{II.1. Descripción del área de estudio}

Localizada en la parte oriental de la región Murciana, esta zona comprende la porción de territorio que se extiende en dirección N-S desde los núcleos de Espinardo, Cabezo de Torres, Monteagudo y Santomera, coincidiendo aproximadamente con la curva de nivel de los $100 \mathrm{~m}$, hasta la vertiente norte de la Sierra de la Cresta del Gallo. El límite E lo 


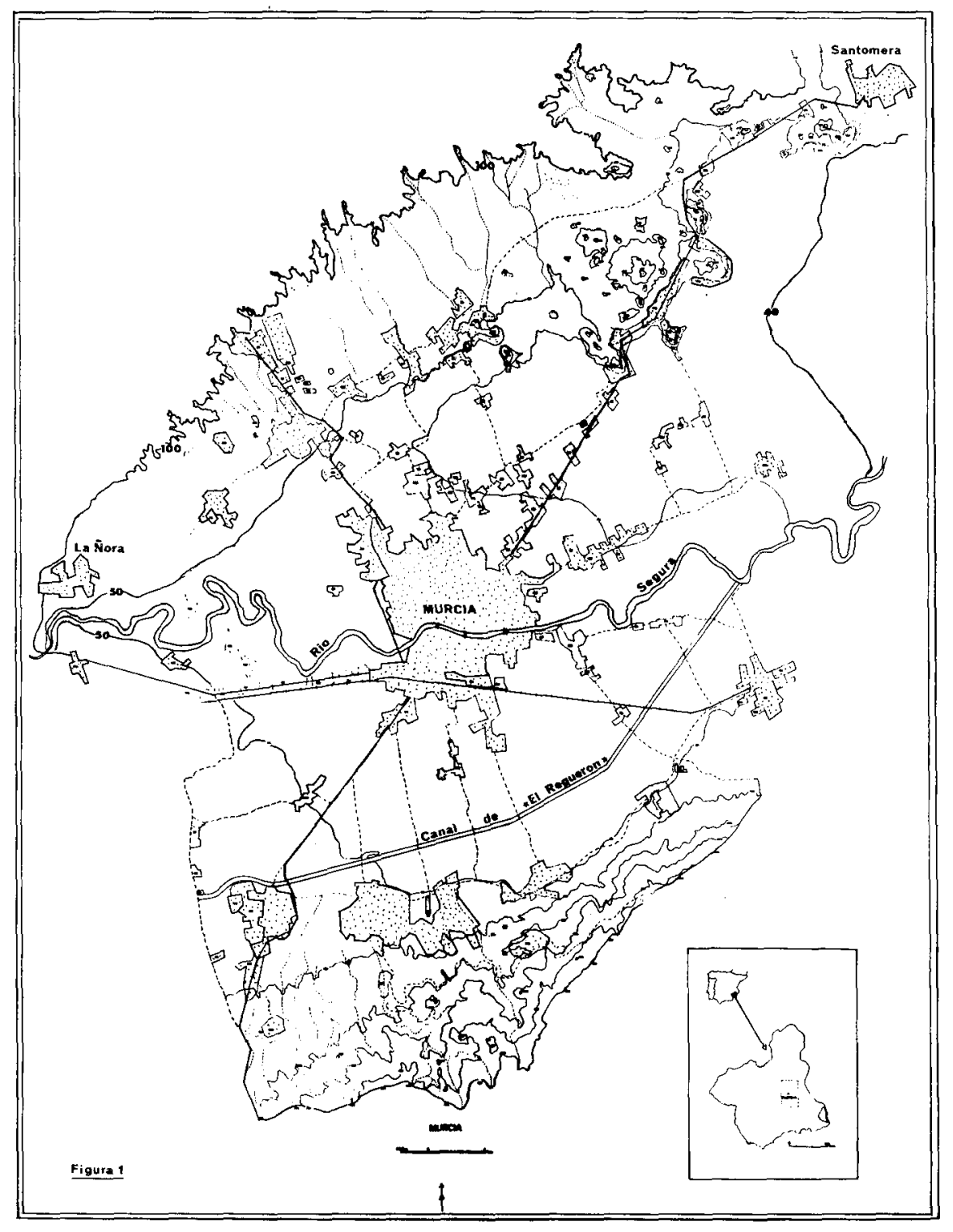


constituye la curva de nivel de los $40 \mathrm{~m}$, y el W una línea imaginaria que coincide con la carretera de Alcantarilla a la Venta de La Paloma (Figura 1).

A grandes rasgos, este espacio queda caracterizado por cuatro sistemas bien definidos:

a) Núcleo urbano de Murcia: este sistema asentado sobre el suelo de vega, ocupa una superficie aproximada de 559 ha. Su principal limitación estriba en las posibilidades de expansión que presenta, las cuales son imprevisibles dada la falta de estudios integrados para identificar el curso óptimo de crecimiento y los cambios que se derivan de éste.

b) Sistema agrícola, que ocupa fundamentalmente el sector de la vega; este sistema, de gran importancia por su elevado potencial productivo, se encuentra afectado por el riesgo de desaparición o alteración profunda debido a la presión urbanizadora, que está originando un cambio en los métodos tradicionales de agricultura.

c) Zona de montaña: parte del ella sometida a la localización de viviendas secundarias. Este sistema de características peculiares está llamado a constituir el Parque Regional de Murcia (ampliando el Parque Natural del Monte El Valle, ya creado) por la notable importancia en algunos puntos de los procesos geológicos-geomorfológicos, así como por la particularidad de la vegetación y fauna que posee. Todo ello le confiere un alto valor como zona de esparcimiento de la aglomeración urbana de Murcia.

d) Area industrial: este sistema se localiza fundamentalmente sobre suelos de baja productividad, si bien afecta a determinados puntos de la vega (industrias conserveras, edificios para almacenamiento de productos agrícolas, etc.) lo que constituye una amenaza para este sector productivo.

Este conjunto de actividades, cada una de ellas son una capacidad de respuesta sobre el medio muy diferente, han de ser coordinadas e integradas en un espacio limitado, lo que requiere una evaluación de las 'modificaciones que ejerce cada actividad sobre el resto, a fin de plantear una localización óptima a largo plazo, basada en los recursos que encierra el territorio y en un aprovechamiento sostenido de los mismos. 


\section{II.2. Sistema IRAMS}

La metodología seguida en este estudio se denomina sistema IRAMS de Registro y Minimización de Impactos. Este sistema fue elaborado por el Grupo de Análisis Ambiental del Departamento de Ecología de la Universidad de Sevilla (GONZALEZ BERNALDEZ et al., 1974), siendo posteriormente modificado y perfeccionado por RODENAS LARIO (1977) y SANCHO ROYO et al., (1981).

El objetivo esencial del método es evaluar los impactos que se derivan de una serie de utilizaciones concretas localizadas en un territorio conocido, a fin de distribuirlas de forma que se produzca la mínima alteración de los valores ambientales de la zona.

Una descripción general del sistema se puede ver en SANCHO ROYO et al., (1981) y en MARTIN DE AGAR et al., (1982), concretándonos en este estudio en los aspectos metodológicos referentes a su aplicación en la zona que nos ocupa.

Las etapas de que consta el sistema son tres:

1. Prospección y sectorización.

2. Diagnosis y valoración de impactos.

3. Archivo y cartografía de impactos.

Como ya se señaló en el apartado anterior, en este trabajo nos vamos a referir únicamente a la primera fase, dejando para una publicación posterior las dos fases restantes.

La prospección y la sectorización consiste en la obtención de datos ambientales y división del territorio en sectores o unidades cartografiables para cada tema o aspecto del medio. La escala de trabajo utilizada ha sido $1 / 18.000$, que coincide con la del vuelo fotogramétrico realizado en 1977 por el Ministerio de Agricultura.

La prospección a su vez comprende dos aspectos fundamentales:

- Explotación de la documentación existente sobre la zona de estudio (bibliografía, cartografía y fotografía aérea).

- Recorridos de campo apoyados en la fotointerpretación. 
En cuanto a los temas analizados, éstos han sido nueve:

- Clima

- Geología-Litología

- Hidrología superficial y subterránea

- Geomorfología

- Suelos

- Vegetación

- Fauna

- Usos del suelo

- Paisaje

Cada uno de los temas ha sido estudiado por separado, dejando para una fase posterior la labor de integración de la información recogida. En cada caso, la metodología de prospección ha sido distinta según el material de que se disponía para abordarla.

- Tema CLIMA. Para el análisis climatológico se han utilizado los datos de las 11 estaciones meteorológicas existentes en el área de estudio. Además de la observación directa de estos datos y de la realización de diagramas térmicos y pluviométricos, y climodiagramas de WalterGaussen, se ha efectuado un análisis de los parámetros climáticos más representativos (temperaturas máximas y mínimas, precipitación, evapotranspiración real, evapotranspiración potencial, déficit hídrico y reserva hídrica), utilizando técnicas multivariantes de ordenación y clasificación. Con estos análisis se intentaban detectar los sectores que, por sus características mesoclimáticas presentan riesgos potenciales de contaminación por inversión térmica, zonas con elevada capacidad de dispersión atmosférica, fenómenos de visibilidad, etc.

La técnica utilizada en el análisis de la información ha sido la denominada «ordenación jerárquica» (DIAZ PINEDA et al., 1979). Esta técnica consiste en la aplicación simultánea de los métodos de ordenación y clasificación sobre una misma matriz de datos, de forma que los grupos de estaciones obtenidos por la clasificación se puedan utilizar para diferenciar su distribución en el plano de la ordenación, interpretando los resultados en términos de parámteros climáticos mediante un procedimiento de análisis gráfico no lineal.

Dado que el número de estaciones existentes en la zona de estudio 
era muy bajo, y a fin de que la muestra fuera más significativa, se añadieron al análisis las estaciones correspondientes a la otra zona estudiada (el Mar Menor y ecosistemas adyacentes).

Más información sobre el método de análisis utilizado, se puede ver en MARTIN DE AGAR (1983).

- Tema GEOLOGIA-LITOLOGIA. Las unidades o sectores para este tema se han caracterizado en base al origen, composición y disposición de los materiales rocosos y minerales que forman la corteza terrestre.

Como fuente de información, se han utilizado los Mapas Geológicos escala $1 / 50.000$, el Mapa Geotécnico General escala $1 / 200.000$ y el Mapa de Rocas Industriales escala 1/200.000, todos ellos del IGME.

- Tema HIDROLOGIA. Las unidades de hidrología se han caracterizado en cuanto a la permeabilidad de los suelos y profundidad de la capa freática, factores determinantes de la productividad agrícola; también se ha considerado el riesgo de inundación o inundabilidad, puesto que es un factor de indudable importancia en esta zona, pero al que, sin embargo, no se le ha prestado aún la atención necesaria. Para estos aspectos, se han consultado los estudios del I.O.A.T.S. (1963, 1966), CALVO GARCIA-TORNEL $(1969,1982)$, LOPEZ BERMUDEZ et al., (1979), ARENAS CUEVAS (1980) y E.P.Y.P.S.A. (1981).

Respecto a la hidrología superficial, se han caracterizado los cursos del Segura y Guadalentín en base a la calidad de sus aguas, evaluada mediante el sistema de los saprobios, basada en la frecuencia de aparición de organismos típicos según el grado de contaminación de las mismas (organismos indicadores). La información sobre el tema ha sido extraída de los estudios de SUAREZ et al., (1983) y varios autores (1983).

También, dentro de los cursos superficiales, se han señalado las principales ramblas que recorren la zona, las cuales han jugado un papel importante en la formación de los suelos que orlan el piedemonte de las alineaciones limítrofes.

- Tema GEOMORFOLOGIA. En este estudio, se han caracteriza- 
do las principales formas de relieve que configuran el área de estudio, analizándose otros elementos relacionados con ellas y que son esenciales en la planificación: altitud, pendientes, exposición, orientación, erosionabilidad, escorrentía e inundabilidad.

Para ello, se elaboraron primeramente dos mapas por separado, uno de ellos con las formas de relieve predominantes, y otro de pendientes agrupadas en cinco clases:

- Clase 1: áreas con pendiente inferior al $5 \%$

- Clase 2: zonas con pendiente entre el 5 y $10 \%$

- Clase 3: agrupación de pendientes del 10 al $20 \%$

- Clase 4: pendientes del 20 al $35 \%$

- Clase 5: pendientes superiores al $35 \%$

El tercer aspecto que se ha considerado para la caracterización geomorfológica, está relacionado con el riesgo de erosión de cada punto del territorio. Para ello, se dividió el territorio en cinco categorías de erosión, que corresponden a las realizadas por MONTURIOL et al., (1978), parcialmente modificadas, y que están relacionadas con la erosionabilidad intrínseca del suelo, la pendiente y la densidad de vegetación. El grado de erosionabilidad intrínseca se ha dividido en tres clases, que se corresponden con la clasificación realizada por E.P.Y.P.S.A. (1981):

A. Areas muy sensibles a la erosión: erosionabilidad elevada.

B. Areas de sensibilidad media-alta: erosionabilidad moderada.

C. Areas de sensibilidad media-baja: erosionabilidad escasa.

De acuerdo con estas tres clases, y las otras cinco correspondientes a la clasificación de pendientes anteriormente citada, se establecieron cinco clases o categorías de riesgo de erosión. Las características de estas clases se pueden ver en MARTIN DE AGAR (1983).

La conjunción de los tres mapas llevó a la caracterización de las unidades geomorfológicas para cada zona de studio.

- Tema SUELOS. En este estudio, se ha abordado el tema del suelo en cuanto a las principales características y cualidades que han de considerarse en estudios y proyectos de planificación física (textura, estructura, contenido en materia orgánica, resistencia a la erosión, riesgos de inundación, productividad). 
Es notable la falta de estudios detallados y actualizados que permitan disponer de una cartografía básica de los suelos de la zona a una escala adecuada, para abordar estudios de planeamiento territorial. Por ello se ha tenido que recurrir a la bibliografía y cartografía existentes en la actualidad, obviando necesariamente los problemas que se derivan de uso de mapas realizados a escalas considerablemente inferiores a las utilizadas en este estudio, lo que lleva consigo errores en cuanto al grado de precisión de la información cartográfica y en cuanto al nivel de detalle que corresponde a la escala utilizada.

Los estudios consultados son los del I.O.A.T.S. (1963, 1966), E.P.Y.P.S.A. (1981) y CALVO GARCIA-TORNEL (1982).

- Tema VEGETACION Y CULTIVOS. En el estudio de este tema se han seguido dos metodologías distintas, según se tratara de zonas de cultivos, o de espacios con vegetación natural.

En el primer caso, se analizaron los distintos tipos de cultivos y la extensión que ocupaba cada uno de ellos. Se consideraron dos tipos de cultivos:

- Cultivos de ciclo largo

- Cultivos de ciclo corto

Los cultivos de ciclo largo se dividieron, a su vez, en:

-Agrios: naranjos y limoneros, que ocupan grandes extensiones en toda la Vega.

- Otros frutales, principalmente, melocotoneros, albaricoqueros, ciruelos, cerezos, etc.

- Plantaciones de secano: estos cultivos ocupan sectores muy aislados de la Huerta. Sin embargo, se ha creído conveniente diferenciarlos de los anteriores, dada la naturaleza y los requerimientos que presentan, muy distintos de aquéllos.

Para llevar a cabo la caracterización de las unidades de cultivos se hizo una prospección intensiva de la zona mediante recorridos de campo y fotointerpretación simultáneos. La fotografía aérea que se utilizó corresponde al vuelo de 1977 del Ministerio de Agricultura, escala $1 / 18.000$. 
Para el análisis de la vegetación natural, se realizó una prospección extensiva de campo, parcialmente al azar. Inicialmente, se dividió el territorio en sectores o unidades provisionales, basadas en las formas de relieve, altura, exposición y grado de intervención humana. Posteriormente, y con ayuda de la fotografía aérea, se realizó una prospección de campo, haciéndose un inventario de las especies arbustivas y arbóreas que aparecían en cada uno de los sectores delimitados.

El análisis de los inventarios, paralelo a la fotointerpretación, llevó a la obtención de las unidades definitivas, que quedaron caracterizadas por la presencia/ausencia de las distintas especies de matorral y por el grado de densidad de la vegetación arbórea.

- Tema FAUNA. La caracterización de unidades de fauna se ha basado fundamentalmente en las fuentes bibliográficas existentes y en la información directa suministrada por diversos expertos en el tema, consultándose los datos obtenidos por Sánchez Ruiz y Sánchez Onteniente (comunicación personal) en toda el área de estudio, y los de Navarro Medina referentes a la avifauna de la huerta (comunicación personal).

- Tema USO DEL SUELO. En el estudio que nos ocupa, las actividades antropógenas constituyen un porcentaje elevado del territorio siendo, pues, necesario incluirlas en el análisis territorial.

Mediante prospección de campo apoyada en la fotografía aérea escala $1 / 18.000$, se han caracterizado distintos sectores según la naturaleza de las actividades que se localizan en el territorio: asentamientos urbanos de distinto grado, tipos de cultivos, núcleos y naves industriales, actividades extractivas de diversa índole (explotaciones salineras, mineras, etc.), áreas de esparcimiento, etc.

Asimismo, utilizando los datos obtenidos por SUAREZ et al., (1983), se ha realizado una tipificación de las aguas del Segura y del Canal del Reguerón, basada en la naturaleza de los vertidos orgánicos o agrícolas que tienen lugar en estos cursos.

- Tema PAISAJE. En este estudio el análisis y cartografía del paisaje se ha basado en una división del territorio en función de aquellos 
rasgos que se consideraron determinantes del componente externo o perceptible del mismo. Estos rasgos fueron cuatro: relieve, hidrología, vegetación y usos del suelo. La superposición de los mapas correspondientes a estos temas llevó a la obtención de las unidades de paisaje.

Como expresión de los valores plásticos y emocionales, se consideró el factor visibilidad. Diversos autores han puesto de manifiesto la necesidad de conocer las limitaciones físicas del territorio respecto a la percepción visual (WEDDLE, 1969; LITTON, 1973), con objeto de evaluar la medida en que cada área contribuye a la percepción global del paisaje (ZUBBE et al., 1974). En el campo de la planificación física, el análisis de las condiciones de visibilidad que presentan los distintos puntos de un territorio, constituye una herramienta de gran utilidad en la determinación de los impactos que produce la localización de diversas actividades humanas.

En este sentido, una medida de la intervisibilidad resulta muy útil en la localización de aquellas actividades que sea necesario implantar en el territorio pero que no son deseadas visualmente (STEINITZ, 1979).

En el presente trabajo, se ha medido la intervisibilidad de una forma cualitativa, e investigando sólo una parte de las unidades que podrían ser visibles en toda el área de estudio. Concretamente, se han analizado los sectores topográficamente elevados - montes y cabezos- que afloran en la zona de estudio, diferenciando los puntos desde los que se visualiza la huerta, de aquéllos desde los cuales esta zona no es visualizable.

La caracterización de las unidades se llevó a cabo mediante recorridos de campo utilizando simultáneamente los pares estereoscópicos del vuelo de 1977, escala 1/18.000, del Ministerio de Agricultura.

Por último, un elemento esencial en el paisaje rural y agrícola murciano lo constituyen los sistemas tradicionales de elevación de aguas para uso humano.

Por este motivo, se ha creído conveniente señalar en este tema los distintos aparatos - norias, aceñas, artes y ceñiles- que aparecen dispersos por las zonas de estudio. Como principal fuente de documentación se han utilizado los estudios de MONTANER SALAS (1982) y CALVO GARCIA-TORNEL (1982). 


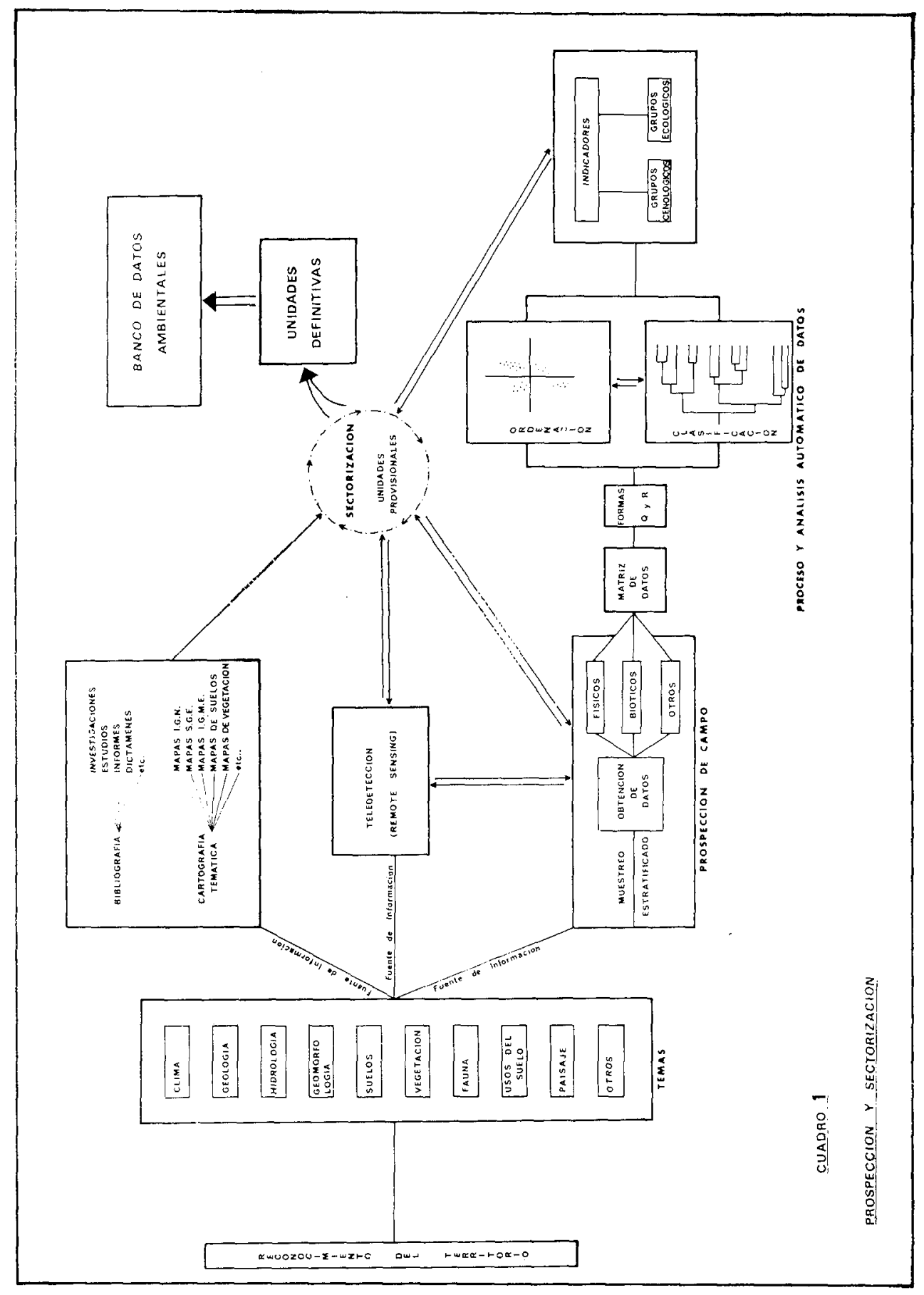


El paso final de esta fase consiste en la codificación y almacenamiento automático de la información recogida.

Para la codificación de los datos se utilizó una malla cuadriculada referida a un sistema de coordenadas $(X, Y)$ con casillas de $1 \mathrm{~cm}^{2}$, que corresponde en realidad a una superficie de 3,24 ha.

Los criterios que se han seguido para la adscripción de las unidades a las distintas cuadrículas son los señalados por RODENAS LARIO (1977) y SANCHO ROYO et al., (1981), y que aparecen descritos en MARTIN DE AGAR y RAMIREZ DIAZ (1984).

Superponiendo la malla a cada uno de los mapas temáticos, se asignó a cada cuadrícula (casilla) la unidad a la que pertenece para cada uno de los temas considerados en el estudio.

En el Cuadro 1 se presenta, de forma esquemática, el proceso de prospección y sectorización temáticas que se ha seguido en este estudio.

\section{RESULTADOS}

Los resultados obtenidos en la fase de prospección y sectorización se concretan en 102 unidades, recogidas en los nueve mapas temáticos que se describen a continuación.

- Tema CLIMA. A partir de la distribución de las estaciones climatológicas en el espacio definido por los tres primeros ejes obtenidos en el análisis de ordenación, y de los grupos de estaciones resultantes de la clasificación por similaridad de los parámetros medidos en éstas, junto con los resultados obtenidos por LEON et al., (1974) y SAURA y FERRERAS (1976), se ha llegado a una caracterización climática aproximada del área de estudio. Se han distinguido cinco unidades que aparecen representadas en el Mapa 1. Estas unidades son:

Unidad 1. Corresponde al núcleo urbano de Murcia y se extiende por todo el sector de Vega. Se caracteriza por unos valores elevados de temperaturas mínimas y de precipitación en primavera. Los vientos pre- 
dominantes son de componente $\mathrm{W}$, siendo el porcentaje de días de calma del $38 \%$, sobre un $65 \%$ de días con vientos inferiores a $6 \mathrm{~km} / \mathrm{h}$ SAURA y FERRERAS, (1976).

Unidad 2. Comprende todo el sector norte del área de estudio, desde Alcantarilla a Santomera. Corresponde al sector más abierto de la zona de Murcia, con valores de temperaturas mínimas inferiores al resto del territorio y valores de precipitación más altos en primavera que en otoño. Los vientos son de componente $\mathrm{E}$ y con abundantes situaciones de calma, principalmente, en la parte de Alcantarilla.

Las Unidades 3 y $\mathbf{4}$ aparecen representadas en el sector de ladera y piedemonte de la Cresta del Gallo en su vertiente N. En esta zona se dan unos valores bajos de mínimas durante todo el año y precipitaciones con valores más altos en primavera (mes de abril) coincidentes con un déficit hídrico alto en noviembre.

No obstante, se pueden diferenciar dos sectores en esta zona, fundamentalmente por los valores de temperaturas máximas en los meses de primavera y verano. El sector de Beniaján (Unidad 3) presenta los valores más altos de máximas de toda la zona de studio, que coinciden con una elevada evapotranspiración potencial y un alto déficit hídrico durante los mismos meses. El resto del sector de ladera (Unidad 4) presenta valores más moderados de máximas, pudiéndose considerar como una zona intermedia entre las unidades 2 y 5 .

Unidad 5. Corresponde a la parte alta de la Sierra de la Cresta del Gallo donde se presentan las máximas más bajas de toda el área de estudio, en primavera y verano. Las mínimas son menos extremás que en el sector de ladera, y las precipitaciones presentan los valores más altos en los meses de marzo y agosto, si bien, a diferencia del resto de la zona de Murcia, también se dan valores elevados de precipitación en invierno, siendo la evapotranspiración de agosto la que tiene mayor valor.

- Tema GEOLOGIA-LITOLOGIA. Geológicamente, la huerta de Murcia puede considerarse como una depresión tectónica que se individualizó durante el Terciario y que sirvió de cuenca de sedimentación de materiales neógenos. Sobre éstos se han acumulado, durante el Cuaternario, materiales de distinta procedencia y naturaleza. 
Las unidades que se han cartografiados para esta zona aparecen en el Mapa 2. Estas unidades son las siguientes:

Unidad 1. Corresponde al Permo-Trias y está constituída, fundamentalmente, por arcillas de distinta tipología y cuarcitas, con intercalaciones de pizarras. En las zonas de la Cresta del Gallo y Espinardo aparecen estratos delgados de carbonatos, ciertos niveles de grawacas y masas de metabasitas.

Unidad 2. Está constituída esencialmente por rocas carbonatadas correspondientes al Triásico medio-superior. En la zona de Loma los Cantalares se distinguen series de rocas carbonatadas de diversa coloración y disposición, con algunas intercalaciones de rocas margosas, piżarras, cuarcitas y yesos. En la región comprendida entre Cobatillas y Santomera, debajo de los tramos de yeso entre las dos series inferiores aparecen masas de matabasitas de espesor variable, llegando a alcanzar, en algunos puntos, decenas de metros.

Unidad 3. Sector de yesos masivos o caóticos, pertenecientes al Triásico que sólo aparecen de forma esporádica en la Sierra de la Cresta del Gallo.

Unidad 4. Esta unidad también del Triásico, aparece sobre la anterior y está formada por dolomías oscuras, bien estratificadas, que alternan con grawacas monogénicas y delgados niveles de pizarras; en algunas zonas, los carbonatos son sobremontados por mármoles dolomíticos negros en bancos gruesos.

Unidad 5. Unidad del Permo-Trías, constituída por filitas plateadas a grises (esquistos grafitosos) y cuarcitas.

Unidad 6. Corresponde a un sector de areniscas margosas del Mioceno medio, que se encuentran bien estratificadas y con algunas intercalaciones de conglomerados e incrustaciones de restos de erizos y algas, trozos de conchas de moluscos, etc.

Unidad 7. Esta unidad aparece muy reducida en la zona, y se encuentra apoyada directamente sobre los carbonatos de la Unidad 4. Corresponde a una serie constituída por conglomerados de cemento areno-arcilloso, de poco espesor, sobre el que se asienta un paquete grueso $(25 \mathrm{~m})$ de margas grisáceas. 
Unidad 8. Unidad del Mioceno medio-superior constituída por conglomerados, a veces fuertemente cementados con cantos poco elaborados y de formas y dimensiones muy distintas, llegando a contener bloques de más de 1 metro cúbico. Su naturaleza es muy diversa, predominando los cantos dolomíticos y esquistos metamórficos.

Unidad 9. Corresponde a una facies marina del Mioceno superior constituída, fundamentalmente, por margas con delgados niveles de areniscas, con un porcentaje elevado de carbonatos y poco material detrítico.

Unidad 10. Esta unidad comprende dos sectores constituídos por conglomerados continentales correspondientes al Mioceno superior, y más concretamente, al Tortoniense superior-Andaluciense. En la parte NW de la zona de estudio, los cantos están bien rodeados y a veces forman bloques unidos a una matriz arcillosa roja, mientras que en el sector de la Cresta del Gallo los clastos están poco rodados, y los elementos de los conglomerados son principalmente dolomíticos, si bien son frecuentes también las cuarcitas, pizarras, etc.

Unidad 11. Glacis correspondiente al Cuaternario reciente, formado por limos grises con cantos heterométricos, de subangulosos a subredondeados, y de muy diversa composición: dolomías, pizarras, cuarcitas, calizas, areniscas, etc. Los limos se encuentran endurecidos por una especie de débil pasta calcárea.

Unidad 12. Al pie de los relieves de la Cresta del Gallo, y en menor superficie en los del sector NW, se encuentra esta unidad del Cuaternario, que corresponde a los conos de deyección, constituídos por una masa caótica de clastos de cuarcitas, pizarras, areniscas, etc.; los tamaños de estos clastos oscilan desde limos y arcillas hasta bloques, frecuentemente cementados por encostramientos calizos. En el sector SW del área de estudio aparece parte del amplio cono de deyección del Guadalentín que ocupa unos $30 \mathrm{~km}^{2}$, hasta alcanzar las cercanías del núcleo urbano de Murcia (CALVO GARCIA-TORNEL, 1969). Corresponde al delta interior por el que el Guadalentín desembocaba en otro tiempo al Segura, y está constituído por las aportaciones de sedimentos del río en su antiguo divagar por este sector antes de ser canalizado; el empuje de estos materiales ha desviado hacia el $\mathrm{N}$ el cauce del Segura (CALVO GARCIATORNEL, 1982). 
Las Unidades 13 y 14, también del Cuaternario, corresponden, respectivamente, a las terrazas inferior y superior donde se sitúa la huerta de Murcia. Están formadas fundamentalmente por limos rojos oscuros a pardos. La terraza superior corta mediante un escarpe a los conos de deyección de la unidad anterior aunque, a veces, éste contacto es difuso, sin que llegue a existir ninguna diferencia topográfica y, además, la intensa actividad agrícola ha alterado profundamentè la topografía original (CALVO GARCIA-TORNEL, 1982).

Por último, la Unidad 15 son sedimentos dejados actualmente por arroyos y ramblas de escasa longitud. Estos sedimentos están formados por limos grises a rojizos.

- Tema HIDROLOGIA. En la Vega de Murcia, las frecuentes inundaciones del Segura y del Guadalentín han depositado sucesivas capas arcillosas poco permeables, a las que se han unido las arcillas de horizontes superiores lavados por una iluviación muy activa causada por el riego continuo. Como resultado de esta acumulación, se ha originado una capa arcillosa, muy potente en los horizontes inferiores, que actúa como superficie impermeable sobre la que se detiene el agua.

En el Mapa 3 aparecen representadas las ocho unidades de Hidrología que se han caracterizado para la zona de Murcia.

Unidad 1. Corresponde a las zonas en las que el nivel freático se encuentra próximo a la superficie (entre 0 y $2 \mathrm{~m}$ ), debido a la presencia de materiales poco permeables, de textura fina en general, y que presentan a poca profundidad la capa impermeable descrita anteriormente, que obstaculiza el drenaje.

Unidad 2. Corresponde a los sectores de Vega donde el nivel freático se encuentra a una profundidad de $2,1 \mathrm{~m}$ a $5 \mathrm{~m}$. En general, son suelos profundos formados por acumulación de sedimentos gruesos por el choque durante el Cuaternario de las corrientes del Segura y el Guadalentín al confluir en la fractura tectónica de la Vega que iban rellenando (I.O.A.T.S., 1963). Esta unidad también se presenta al pie de las laderas de los relieves que circundan la Vega al norte y al sur, en la franja de suelos profundos constituídos por los materiales de derrubios de los cabezos circundantes. 
La Unidad 3 corresponde a los sectores de suelos pedregosos y suelos pardo-calizos profundos, de naturaleza semipermeable, situados en zonas donde la topografía presenta una elevación suficiente para que el nivel freático quede profundo (más de $5 \mathrm{~m}$ ). También se incluyen en esta unidad los suelos pardo-calizos en complejo con serosem margoso, de las laderas de la Cresta del Gallo; éstos son de naturaleza poco permeable $y$, al estar en pendientes, recogen poca agua por filtración. No obstante, hoy día, estos suelos se encuentran profundamente transformados por las actividades agrícolas y dispuestos en bancales, aumentando así la retención hídrica.

Unidad 4. Corresponde a las zonas más bajas de ribera de los dos cursos fluviales, Segura y Guadalentín, que constituyen los lechos de inundación estacionales o episódicos.

Según LOPEZ BERMUDEZ et al., (1979), la causa de las grandes crecidas que se registran en los cursos de agua murcianos es, fundamentalmente, la dinámica climática regional, que se caracteriza por una marcada inestabilidad derivada de la convergencia de los factores orográficos y la formación en altitud de «gotas frías» que originan abundantes y violentas precipitaciones. Aunque el hombre ha modificado notablemente los cursos de los ríos Segura y Guadalentín (suprimiendo meandros, construyendo muros de defensa y pantanos de reserva y regulación), la amenaza de inundaciones persiste, debido en muchos casos, a una deficiente planificación y gestión de los recursos hídricos.

Unidad 5. Corresponde a los cabezos y vertientes que bordean la Vega. En éstos, los materiales son, en general, pocos permeables, dándose inflitraciones por porosidad y fracturación en aquellos sectores en los que la pendiente lo permite.

En los tramos en los que se desarrolla una vegetación densa, aumenta en cierta medida la retención hídrica, si bien la litología, bastante desfavorable, hace que sea mayor la escorrentía que la infiltración.

Las unidades siguientes corresponden a los lechos fluviales, y más concretamente a la calidad de sus aguas, distinguiéndose éstas en dos tipos:

Unidad 6. Corresponde a los tramos del Segura y el Guadalentín ca- 
racterizados por una contaminación hídrica muy elevada (aguas poli y $\alpha$-mesosapróbicas) a causa de los vertidos y cargas, orgánica y agrícola, que van directamente a los cauces.

Las comunidades que subsisten a estas cargas son únicamente bacterias anaerobias de tipo filamentoso (como Sphaerotilus natans), algunos tubífidos (Tubifex sp.) y abundantes larvas de insectos, fundamentalmente Dípteros (Chironomus, grupo Thummi: Eristalis sp; etc.).

En el sector de Beniaján, los vertidos de este núcleo y de otros adyacentes son recogidos en la estación de depuración de Beniaján, la cual no funciona y por tanto los vertidos pasan tal cuales a El Reguerón. (Actualmente se ha dado una solución al problema que presentaba la falta de depuración de las aguas de la zona, que provocó la consiguiente queja de los vecinos de aquella pedanía. Esta solución consiste en enviar los vertidos directamente al río Segura a través de un tubo emisario que va desde la depuradora al río). De ahí que a partir del punto en que confluyen los dos cauces, la carga contaminante sea considerable (aguas polisapróbicas).

Unidad 7. Corresponde a aguas con contaminación moderada (aguas $\beta$-mesosapróbicas).

Las comunidades que se desarollan en estas aguas, si bien son banales, tienen interés por la diversidad de especies que las componen, especies todas ellas tolerantes a un grado medio de contaminación orgánica. Entre las más características cabe señalar algunos Hirudineos, Coleópteros acuáticos (Lacophilus hialipus, Hydrophilus pistaceus), y Planarias Dugesia policroa); un gran número de moluscos (Potamopyrgus jenkinsi y Physa acuta, principalmente) y un pez, Gambusia affinis, que se presenta muy abundante en aguas de este tipo.

Unidad 8. Esta última unidad corresponde a los cursos esporádicos (ramblas) más importantes que recorren los relieves circundantes de la zona de Murcia. Excepto la Rambla del Puerto que llega mediante un canal hasta El Reguerón, las demás son arreicas no alcanzando éstas ninguno de los cursos de agua permanente.

El depósito de los materiales que arrastran en su recorrido, mucho más gruesos que los aportados por los ríos, forman una orla discontinua de suelos en pendiente en el fondo del valle (conos de derrubios). 
- Tema GEOMORFOlOGIA. A grandes rasgos, desde el punto de vista geomorfológico, la zona de Murcia puede resumirse en una depresión prelitoral por donde discurre el cauce del Segura y, a los lados, dos alineaciones montañosas. El valle corresponde al fondo de la Depresión y aparece como un plano ligeramente inclinado hacia el NE. La alineación del Norte está formada por los cerros y cabezos permotriásicos que emergen aislados en un dominio de calizas, margas y conglomerados miopliocenos, y que presentan alturas inferiores a 300 metros. La otra alineación, que flanquea la Depresión al Sur, corresponde a la Sierra de la Cresta del Gallo, reborde montañoso prelitoral de estructura compleja, constituído por materiales paleozoicos y mesozoicos de pizarras, cuarcitas, margas yesíferas, areniscas y dolomías (SANCHEZ SANCHEZ, 1980).

Las unidades de relieve que se han determinado para la zona de estudio aparecen representadas en el Mapa 4 y son, las siguientes:

Unidad 1. Corresponde a la llanura aluvial formada por la confluencia de los ríos Guadalentín y Segura. Se trata de un amplio valle de terrenos cuaternarios con materiales de limos y arcillas de un espesor considerable, distribuídos en diversos niveles y con desigual desarrollo superficial; sobre estos terrenos se asientan la huerta y la ciudad de Murcia.

También se ha incluído en esta misma unidad el sector de terrazas que aparece en continuidad y extensión a lo largo del curso del Segura; corresponden a los niveles de depósitos que ha ido dejando el río en su recorrido, describiendo amplios meandros y excavando sus propios sedimentos.

Unidad 2. Corresponde a los conos de derrubios formados por materiales detríticos procedentes de los relieves más elevados de la Sierra de la Cresta del Gallo y transportados bien por gravedad, bien por escorrentía de las aguas superficiales, o bien por ambos fenómenos a la vez. Los depósitos de estos conos son heterométricos, pocos rodados y, actualmente, se encuentran alterados debido a las técnicas de abancalamiento realizadas para la puesta en cultivo de estas zonas.

Unidad 3. Corresponde a los sectores de glacis, formas de pendiente topográfica muy débil (de 5-10\%), que se desarrollan sobre materiales 
blandos pocos rodados. En la mayor parte de la zona de Murcia estos sectores son utilizados para la agricultura excepto en el sector $\mathrm{N}$ de Espinardo, en el que se asienta el área industrial de Murcia.

Unidad 4. Corresponde a los sectores de montaña, laderas y vaguadas, de topografía poco acusada (pendientes entre 10 y $20 \%$ ) y con exposición a solana. Los riesgos de erosión son moderadamente elevados debido a las características edáficas y la escasez de vegetación que presentan estos sectores, necesitando, cuando se cultivan, prácticas de defensa muy simples.

Unidad 5. Corresponde a los sectores de montaña constituídos por suelos con escasa erosionabilidad intrínseca, que se encuentran en pendiente acentuada (más de 35\%), y suelos de erosionabilidad intrínseca elevada, situados en pendiente moderada o ligeramente acentuada (de 10 a $35 \%$ ). Estos sectores presentan un riesgo de erosión elevado, precisando prácticas de defensa muy complejas para ser cultivados.

Unidad 6. Corresponde a los sectores de monte donde los riesgos de erosión son muy elevados. Los suelos de esta unidad se presentan en pendientes muy acusadas (más del $35 \%$ ) y la erosionabilidad intrínseca es escasa a moderada. También se incluyen en esta unidad los sectores de suelos con erosionabilidad intrínseca elevada situados en pendientes moderadamente acentuadas (20-35\%). Por tanto, salvo en las zonas en donde se desarrolla una vegetación densa, los sectores incluídos en esta unidad se encuentran expuestos a importantes fenómenos de denudación y abarrancamiento.

Unidad 7. Corresponde a los cursos fluviales naturales o artificiales que discurren por la Vega, atravesándola de W a E. Estos cursos constituyen en sí mismos unas unidades muy peculiares con una dinámica hidrológica propia, de enorme interés en estudios de planificación.

Debido al escaso declive de la depresión hacia el NE, el Segura presenta un curso característico de llanura aluvial, en donde describe amplios meandros, y en los sectores donde el río ha excavado sus propios sedimentos, se revelan acumulaciones lenticulares de grava menuda y arenas producidas por los cambios de velocidad y caudal.

El río Guadalentín, antes de ser canalizado se caracterizaba por su 
carácter torrencial, recorriendo en distintas direcciones la masa de sedimentos que forman el delta interior por el que este curso confluía con el Segura.

Tanto el Segura como el Guadalentín son cursos fluviales claramente mediterráneos, con unos rasgos hídricos muy marcados: caudal medio muy variable y crecidas desmesuradas con fenómenos periódicos de inundación que han originado el depósito de los materiales aportados por los ríos, constituyendo así la famosa vega murciana. No obstante, estas inundaciones beneficiosas han tenido también en numerosas ocasiones consecuencias catastróficas, provocando importantes pérdidas materiales y humanas.

Con el fin de solucionar en parte estas catástrofes, se han realizado importantes obras hidráulicas en los cursos, que han ayudado a disminuir los efectos de estas avenidas, si bien, la progresiva colmatación de los embalses, el arrastre de los suelos por la deforestación, el escaso o nulo control hidráulico en las grandes ramblas (Amarga, Judio, Moro, Tinajón...), etc., hacen que la amenaza aún persista.

- Tema SUELOS. Los suelos que constituyen la vega murciana son suelos alóctonos, originados, en su mayoría, a partir de los materiales arrastrados por el Segura, el Guadalentín y diversas ramblas que recorren las sierras próximas a la vega, y llegan hasta la misma: Rambla del Puerto de la Cadena, Rambla Salada, Rambla de la Cresta del Gallo, etc. La composición de los aluviones aportados por estos cursos es muy compleja, predominando los elementos arcillosos fundamentalmente en el sector SW del Valle, que recibía los aportes del Guadalentín. En menor proporción aparecen otros elementos como son margas, areniscas, arenas y calizas (CALVO GARCIA-TORNEL, 1982).

Los suelos de vega se caracterizan por un contenido elevado de carbonato cálcico, que dificulta la presencia de otros elementos como son el fósforo, el hierro y el manganeso, y también de materia orgánica debido a la intensa actividad microbiana que suele tener lugar en los suelos calizos. Actualmente, estos suelos de vega se encuentran profundamente alterados debido a las distintas labores agrícolas intensivas a que han sido sometidos por el hombre.

En las alineaciones montañosas que delimitan el valle se presentan 
suelos poco o nada evolucionados, litosuelos, de naturaleza variable según los materiales originales. Al pie de estas alineaciones se han formado suelos superficiales, de textura gruesa, que corresponden a derrubios de los materiales de las partes altas de las sierras, que han sido arrastrados por las ramblas o por gravimetría.

En el Mapa 5 se han representado las ocho unidades de suelos en que se ha dividido el área de Murcia. Estas unidades son las siguientes:

Unidad 1. Corresponde a los suelos de vega, profundos y permeables, de composición areno-limosa, que se extienden por todo el sector W del valle, donde tenían lugar las aportaciones del Guadalentín en su antiguo recorrido, y en el sur, en las proximidades de Beniaján. También, en las orillas del Segura y en los bordes de la huerta, estos suelos forman una estrecha banda, con un predominio de los elementos arenosos debido al depósito de elementos gruesos en los desbordamientos del río, y a los arrastres de ladera, respectivamente.

Unidad 2. Corresponde a suelos de vega poco profundos, de textura mucho más fina que los anteriores, y que presentan a escasa profundidad una capa de arcilla que forma un horizonte gley que obstaculiza el drenaje; en algunos puntos esta capa está en la superficie y los suelos se encuentran frecuentemente inundados, lo que impide el desarrollo de cultivos de raíces profundas, exigentes en oxígeno.

Unidad. 3. Corresponde a litosuelos calizos constituídos por calizas dolomíticas muy erosionadas, con suelo pardo superficial en las oquedades de las rocas y en los sectores de menor pendiente. Estos suelos se presentan en el Norte, en los cabezos triásicos de Cobatillas, La Cueva y Monteagudo, si bien es en el sector de la Cresta del Gallo donde alcanzan su mayor extensión. En el sector W de esta tierra, entre las ramblas del Valle y de la Paciencia, aparecen diversos afloramientos de yesos, algunos de los cuales han sido explotados hasta hace pocos años (sector de Las Canteras). Actualmente, se encuentran en gran parte desmantelados, y los yacimientos han sido abandonados.

Unidad 4. Corresponde a suelos pardos-calizos originados por acumulación de derrubios de los anteriores. Son suelos pedregosos, permeables, y con una gran proporción de carbonatos. Estos suelos se extienden por todo el sector norte, en las inmediaciones de Espinardo y Guadalu- 
pe, al pie del Cerro de Cobatillas y de la Loma del Barranco Largo. En la Sierra de la Cresta del Gallo estos suelos aparecen delimitados en el sector $\mathrm{W}$, en donde la pendiente es moderada.

Unidad 5. Corresponde a litosuelos silíceos con tierra parda superficial que aparecen en los cerros y cabezos constituídos por materiales pérmicos (Esparragal, Campillo, Cabezo de Torres, Monteagudo, Bermejo, etc.). La composición es de cuarcita y pizarras arcillosas, en algunos puntos micáceas, fácilmente resquebrajables, desarrollándose en los intersticios una vegetación xerofítica que contribuye a la destrucción de la roca y a la formación de suelo superficial.

Unidad 6. Corresponde a los sectores de tierras pardas sobre esquistos silíceos, que ocupan las laderas de los montículos señalados en la unidad anterior. En las laderas las tierras son superficiales, mientras que en las zonas inferiores presentan un mayor desarrollo. La proporción de carbonatos es baja, apareciendo únicamente cuando en su composición entran silicatos de calcio o de magnesio.

La proporción de grava en estos suelos es elevada y la estructura poco desarrollada, de tipo granular. Sin embargo, la permeabilidad es baja debido a la forma laminar de las fracciones finas y arenosas.

Unidad 7. Corresponde a los sectores constituídos por depósitos coluviales de laderas de monte o conos de deyección de torrentes pleistocénicos procedentes de las sierras cercanas. La textura es arenosa o limoarenosa, y la estructura débil y granular. La elevada proporción de grava hace que los suelos sean muy permeables y tengan una baja capacidad de reteeción hídrica.

Unidad 8. Corresponde a suelos pardo-calizos pedregosos asentados sobre margas, con una fracción de limos y arcillas en los estratos más profundos. Estos suelos ocupan una porción muy reducida del área de estudio, apareciendo únicamente en las proximidades de Algezares.

- Tema VEGETACION Y CULTIVOS. La situación actual en la huerta de Murcia se caracteriza por el predominio de los cultivos de regadío, si bien, no es extraño encontrar aún higueras que, normalmente, se localizan en los márgenes de las parcelas, y algunos almendros y olivos en pequeñas extensiones. 
En cuanto a la localización de los cultivos, éstos no presentan ningún «pattern» o modelo de distribución respecto a las características físicas del terreno. Ello es debido fundamentalmente a la abundancia de propiedades muy poco extensas. Del total de propietarios que existen en la huerta (unos 13.000 aproximadamente), el $83 \%$ posee menos de 1 ha, y un $14,7 \%$ dispone de superficie entre 1 y 10 ha, abarcando entre ambos grupos cerca del $75 \%$ de la superficie total (CALVO GARCIATORNEL, 1971). Esto, unido a la necesidad de obtener el máximo provecho de la tierra, hace que los cultivos se extiendan de forma desordenada por toda la zona.

Respecto a los tipos de herbáceas que se cultivan en la huerta, debido a la frecuencia con que son sustituídas unas por otras, no ha sido posible diferenciarlas en el Mapa de Vegetación y Cultivos. No obstante, se pueden señalar como más frecuentes la patata, la judía, y el haba entre las hortalizas y leguminosas, el maiz y la alfalfa entre los cereales y plantas forrajeras.

En cuanto a los frutales no cítricos, a pesar de que las características climáticas y edáficas de la zona no son las adecuadas para su desarrollo, éstos han llegado a ocupar una gran extensión en la huerta, siendo utilizados, en su mayor parte, para la elaboración de conservas.

Los dos frutales de huerta que aparecen más extendidos por la zona, generalmente asociados con agrios, son el albaricoque y el melocotón en sus distintas variedades. Le siguen en importancia los ciruelos y los membrilleros, y en mucha menor extensión, los manzanos y los perales.

Atendiendo a la extensión que ocupan los distintos cultivos, y al tipo de distribución que presentan, se han obtenido 12 unidades para el sector de la Huerta. Estas aparecen representadas en el Mapa 6 y son las siguientes:

Unidad 1. Corresponde a los cultivos de agrios que se presentan en plantaciones regulares, acompañados de algunos frutales y, a veces, de cultivos herbáceos. Se localizan, principalmente, en los bordes de la vega, en los sectores de piedemonte de los relieves que circundan la huerta, donde alcanzan una gran extensión. De las dos variedades principales, limonero y naranjo, la primera ocupa todo el borde NW y algunos sectores del flanco S. El naranjo, por el contrario, aparece con mayor abundan- 
cia en los pies de ladera de la Cresta del Gallo, desde La Alberca hasta Beniaján.

Unidad 2. Corresponde a los sectores ocupados por frutales de hueso en sus distintas variedades: melocotonero, albaricoquero, ciruelo, etc. Estos ocupan del 70 al $80 \%$ de la unidad y, asociados a ellos, se presentan algunos cítricos y escasos cultivos herbáceos. Se localizan preferentemente en el sector $\mathrm{W}$ de la huerta, alcanzando las mayores extensiones en las márgenes del río Segura.

Unidad 3. Corresponde a los sectores donde los cultivos predominantes son herbáceas con algunos frutales intercalados. Las especies más extendidas son la alfalfa, el maiz, la patata, la judía y el haba. Estos cultivos se localizan preferentemente en el centro de la huerta, desde Santomera hasta Patiño, coincidiendo con los sectores de nivel freático superficial.

Unidad 4. Esta unidad corresponde a aquellos sectores en donde los frutales se encuentran alternando con agrios en la misma proporción. Las especies que suelen ir asociadas son melocotoneros, albaricoqueros y limoneros. Se localizan fundamentalmente en la parte $\mathrm{W}$ de la huerta, desde Murcia a Puebla de Soto.

Unidad 5. Corresponde a cultivos de agrios que se presentan aislados, y en formaciones densas y regulares. Estas plantaciones corresponden a las dos especies de naranjo y limonero, en sus distintas variedades, siendo más abundantes los segundos que los primeros.

En general, esta unidad se localiza en los bordes de la Vega, alcanzando las mayores extensiones en el sector $\mathrm{N}$, desde La Nora hasta Guadalupe, y de Churra a Santomera. En el sur, ocupan una franja más estrecha que atraviesa también los distintos núcleos urbanos, desde La Alberca hasta Beniaján. También ocupan un amplio sector en las márgenes del río Segura, yendo de Murcia a Alquerías.

Unidad 6. Corresponde a sectores donde aparecen los frutales aislados, sin ningún cultivo asociado. Esta unidad se encuentra muy reduci$\mathrm{da}$, pues la necesidad de aprovechar al máximo y a corto plazo la superficie de las parcelas, lo más frecuente es que vayan asociados a otros cultivos, fundamentalmente de ciclo corto. 
Unidad 7. Corresponde a los cultivos simultáneos de frutales y herbáceas, estando ambos en la misma proporción. Entre los cultivos asociados, el más característico es el de frutales y patatas, de las que se obtiene una cosecha anual (CALVO GARCIA-TORNEL, 1982).

Unidad 8. Corresponde a pequeños sectores muy localizados, donde aparecen los cultivos herbáceos sin agrios ni frutales asociados, reduciéndose estos últimos a los márgenes de las parcelas.

En raras ocasiones estos cultivos se presentan simultáneos; se trata, generalmente, de plantaciones familiares, siendo mucho más frecuente la práctica de rotaciones anuales. Los tipos de plantaciones que se realizan con esta técnica son muy variados; no obstante, se puede señalar como más caractreístico el de maiz y patata, al que algunas veces se encuentran asociados otros cultivos (habas, judías, etc.).

Unidad 9. Dentro de esta unidad se recogen aquellos sectores donde se dan simultáneamente agrios, frutales y herbáceas, en la misma proporción. Generalmente, los cultivos arbóreos se encuentran en plantaciones regulares, alternando unos tipos con otros y, entre ellos, se disponen las hortalizas.

La Unidad 10 corresponde a las zonas de nuevos regadíos que se localizan alrededor de los regadíos tradicionales, en las laderas de las alineaciones que flanquean la huerta a ambos lados.

Si bien el tipo de cultivo, agrios en su totalidad, es similar al de la Unidad 5, la localización y disposición de las plantaciones mediante técnicas de abancalamiento, conlleva una transformación del suélo, y del paisaje en general, a la vez que presenta unos requerimientos hídricos diferentes a los de los cultivos tradicionales.

Unidad 11. Esta unidad, localizada en puntos aislados del sector E de la huerta, corresponde a pequeñas parcelas de cultivos de herbáceas asociados a agrios, con escasos frutales intercalados. Normalmente, los cultivos de suelo se realizan cuando los árboles aún no han empezado a producir; no obstante, esta práctica es mucho más frecuente con los otros frutales que con los agrios.

Unidad 12. Corresponde a los pequeños sectores de cultivo de seca- 
no (olivos, algarrobos, viñedos) que aparecen muy esporádicamente en algunos puntos de la huerta, como restos de la antigua agricultura que se practicaba en este sector.

En las zonas que se señalan en el mapa, estos cultivos se presentan en formaciones regulares, muy abiertas y generalmente, en un estado de abandono muy avanzado (excepto los viñedos). Aún es frecuente encontrar individuos aislados de olivos, principalmente en las proximidades de Los Garres y Beniaján.

Dentro de los sectores con vegetación natural, la mayor extensión corresponde a la Cresta del Gallo y Parque Nacional de El Valle. La situación actual en esta zona muestra una acentuada regresión de las comunidades vegetales originales, debido a las diversas actividades humanas a que se ha visto sometido este sector: pastoreo intensivo, tala para obtención de madera, trazado de caminos y carreteras asfaltadas, etc. Ello, unido a las condiciones de extrema aridez que imperan en toda la región hacen difícil la regeneración de la vegetación original.

Fitosociológicamente, diversos autores apuntan esta zona como dominio potencial de un matorral espinoso (As. Chamaeropo-Rhamnetum) y, en menor extensión, de un encinar (As. Querco lentiscetum) (FERNANDEZ GALIANO y NOVO; 1965; BOLOS, 1967; ESTEVE CHUECA, 1972). Esta última asociación presenta un enorme interés ya que su localización en este sector representa una anomalía muy llamativa en medio del piso infrailicino circundante (González Bernáldez, comunicación personal).

Prácticamente toda la zona se encuentra intensamente repoblada con pino carrasco (Pinus halepensis), bajo el cual se presenta toda una serie de comunidades que son etapas muy degradas de la comunidad original.

Atendiendo al sustrato, a los riesgos del relieve más característicos y al diferente grado de humanización, se han caracterizado ocho unidades de vegetación para los montes y cabezos que se consideran en este estudio. Las unidades son las siguientes:

Unidad 13. Corresponde a pequeños tramos de las ramblas y vaguadas de la Cresta del Gallo en los que aparece el baladre (Nerium 
oleander) como especie característica, junto con otras menos abundantes (Schoenus nigricans; Phragmites sp. Juncus sp., etc.).

En el Barranco del Sordo, en los sectores mejor conservados y con exposición de umbría, se presentan restos de bosques de galería, siendo las especies más características la zarzaparrilla (Smilax aspera), Rhamnus lycioides, el aladierno (Rhamnus alaternus), Rhamnus oleoides, Rubus ulmifolius, y la madreselva (Lonicera implexa), entre otras.

En las vaguadas más abiertas y que aún se mantienen en buen estado, junto con $N$. oleander, aparecen algunos ejemplares de Olea europaea var. oleaster, palmito(Chamaerops humilis), cada (Juniperus oxycedrus) y Coronilla juncea. Normalmente, asociadas a esta comunidad, aparecen especies nitrófilas, como Dorycnium pentaphyllum, más abundantes conforme a la influencia humana se hace más acusada.

Unidad 14. Corresponde a los sectores de ramblas y vaguadas de la Cresta del Gallo que se encuentran muy degradadas, apareciendo $D$. pentaphyllum como especie dominante, junto con la olivarda (Dittrichia viscosa) y Oryzopsis miliacea, mientras que la comunidad original ha desaparecido casi por completo, quedando únicamente algunos vestigios en puntos muy aislados. También se incluyen en esta unidad las ramblas y cursos esporádicos del sector norte del área de estudio. En éstas, las especies nitrófilas se presentan en toda su extensión, junto con algunos individuos de pino carrasco y de algarrobo (Ceratonia siliqua).

Unidad 15. En esta unidad se recogen aquellas zonas de roquedo y taludes calizos en los que, debido a la ausencia de un suelo desarrollado, la vegetación que se presenta es muy escasa y típicamente rupícola: $H y$ pericum ericoides, uña de gato (Sedum sediforme), Dianthus malacitanus, Sarcocapnos enneaphylla ssp. crassifolia, alcaparra (Capparis spinosa), etc.

Unidad 16. Corresponde a los sectores de pino carrasco en donde los individuos se presentan en formación abierta, asociados a un matorral poco denso y achaparrado (garriga). Las especies más características son el romero (Rosmarinus officinalis), la albaida (Anthyllis cytisoides), el romerillo (Helianthemun syriacum), H. viscarium, Teucrium cartaginense, $T$. pseudochamaepitys, T. capitatum, siempreviva (Helicrysum stoechas), avena (Helictotrichon sp.) Thymus hiemalis, etc. 
En los sectores donde existe ya un suelo más desarrollado es frecuente la presencia de vegetación pseudoesteparia, fundamentalmente esparto (Stipa tenacissima), y también algunos retazos de la vegetación climácica.

Unidad 17. Constituída por un matorral denso y un bosque de pino carrasco en formación cerrada, esta unidad recoge aquellos sectores donde se presentan manchas muy reducidas de la vegetación climácica, apareciendo ésta muy fragmentada: palmito, coscoja (Quercus coccifera), retama (Retama sphaerocarpa), adelfilla (Bupleurum fruticosum), cada, esparraguera blanca (Asparagus albus), etc.

En las zonas próximas a las vaguadas, las especies presentan un porte mayor y, generalmente, llevan asociadas a ellas otras especies típicas de sectores umbríos: $R$. lyciodes, $O$. europaea var. oleaster, $N$. oleander, etc.

Unidad 18. Corresponde a los sectores de margas yesiferas que aparecen en las proximidades de la rambla del Valle y en el mismo cauce de ésta, en su tramo medio. En dichas zonas, junto con las especies características de la Unidad 14, aparecen otras típicamente gipsícolas, como son Ononis tridentata y Teucrium libanotis.

Unidad 19. Corresponde a unos sectores de extensión muy reducida, en los que se presentan restos de un encinar húmedo perteneciente a la asociación Rubio-Quercetum, junto con un matorral serial de mirto (Mirthus communis). Además de la coscoja, aparecen como especies más características Rubia peregrina ssp. longifolia, Brachipodium retusum, Clematis flammula, Carex halleriana, y la zarzaparrilla (S. aspera). También se observan en esta zona algunas introgresiones de las otraś comunidades: Ch. humilis, O. europaea var. oleaster, etc.

Dentro de esta unidad se incluye otro sector de encinar menos húmedo que, si bien se encuentra más degradado que el citado anteriormente, merece incluirse junto con aquél a efectos de evaluación por ser las áreas de la Sierra donde se encuentra esta unidad mejor representada. Esta zona está enclavada entre cultivos de secano (olivos), y la superficie que ocupa es bastante amplia, aunque los ejemplares de coscoja se presentan muy esparcidos, e incluso en diversos puntos aparecen dominados por especies de otras comunidades: Ch. humilis, $R$. lycioides, Asparagus stipularis, etc. 
Unidad 20. En' esta unidad se recogen las áreas de recreo de El Valle Perdido y de El Valle de San Juan, en las cuales se presenta una vegetación muy característica constituída por pino carrasco, bajo el cual no existe ningún tipo de matorral debido a las actividades de los visitantes que afluyen a la zona (pisoteo, corte de ramas para hacer fuego, etc.).

Unidad 21. Corresponde a los sectores degradados y zonas sin cultivar en los que aparece el suelo desnudo, sin ninguna cubierta vegetal. Las mayores superficies de esta unidad se localizan al norte de la huerta, en Espinardo.

Unidad 22. Esta unidad recoge la comunidad de cañas (Arundo donax, $A$. plinii) y carrizo (Phragmites australis) que aparece en los bordes de los cursos de agua del Segura y del Canal de El Reguerón. Generalmente, estas especies se disponen en un cinturón o en bandas, según la proximidad del agua. $A$. plinii es la que se encuentra más cerca del cauce, seguida de $P h$. australis; por último $A$. donax es la que se presenta en las zonas más alejadas.

En el Canal de El Reguerón, a lo largo de todo el cauce, es frecuente encontrar individuos aislados de junco de mar (Juncus maritimus), juncu articulado (J. articulatus), J. subulatus, y Juncia maritima (Scirpus maritimus). También, entre el carrizo, se presentan manchas de anea (Typha dominguesi) (SUAREZ et al., 1983).

- Tema FAUNA. Obviamente, el principal inconveniente que presenta la cartografía de unidades de fauna es la movilidad de los animales, siendo imposible establecer con nitidez unos límites espaciales que reflejan la estructura y dinámica de las comunidades animales que habitan la zona. Por este motio, en la tipificación de las unidades de fauna, las especies que se señalan como características de una unidad son aquéllas que se presentan con una mayor abundancia o frecuencia en ese sector, sin que ello implique el que las especies no aparezcan en otros sectores o biotopos del territorio.

Junto con las especies que aparecen como características de cada unidad, se han señalado como «acompañantes» aquellas otras que se dan en dos o más unidades, sin ocupar ninguna de ellas de forma preferente. 
Respecto a las especies características de los distintos biotopos, se han señalado seis sectores o unidades que aparecen representadas en el Mapa 7, y son las siguientes:

Unidad 1. Corresponde a los cursos de agua y riberas limítrofes del Segura y del Canal de El Reguerón. Debido a la carga contaminante que transportan los cauces de estos cursos, la fauna de vertebrados típicamente acuáticos, así como de aquellos que se presentan estrictamente asociados a este medio, es considerablemente escasa. Tan solo persisten determinadas especies que presentan una gran amplitud ecológica.

Hasta hace pocos años (final de los sesenta), eras frecuente encontrar en las aguas y riberas con vegetación de estos cursos una fauna piscícola mucho más estable y diversificada que la actual: barbo común (Barbus barbus bocafli), fartet común (Aphanius iberus), anguila común (Anguilla anguilla) y sobre todo una abundante población de carpas ( $C y$ prinus carpio). Hoy dia, la comunidad original se encuentra en franca regresión, presentándose únicamente un número reducido de la última especie, y la gambusia (Gambusia affinis), que explota los bordes de ambos cauces.

Entre los reptiles cabe señalar la presencia, cada vez más escasa, de la culebra viperina (Natrix maura) y el galápago leproso (Mauremys caspica), ya extinguido; y entre los mamíferos aún es posible hallar, si bien con relativa escasez, algunos individuos de rata de agua (Arvicola sapidus).

No obstante, la comunidad de vertebrados más abundante la constituyen las aves que viven asociadas al cinturón de cañas y carrizo que crece en las riberas, en donde se encuentra una comunidad característica de este habitat. Aún pueden observarse algunos rálidos, fundamentalmente pollas de agua (Gallinula chloropus), si bien el mayor número de especies corresponde a paseriformes: pájaro moscón (Remiz pendulinus), carricero común (Acrocephalus scirpaceus), etc.

Como especies esporádicas cabe señalar la agachadiza común (Gallinago gallinago), el andarios chico (Tringa hypoleucos) y el martín pescador (Alcedo atthis), entre otros. 
Unidad 2. Esta unidad comprende toda el área de huerta en donde la gran variedad de habitats determinada por los distintos cultivos y actividades humanas, permite el desarrollo de una fauna estructuralmente más diversa.

Entre los reptiles se encuentran numerosos individuos de culebrilla ciega (Blanus cinereus), lagartija ibérica (Podarcis hispanica) y, en las paredes de las viviendas que existen entre los cultivos, la salamanquesa común (Tarentola mauritanica). También en las acequias aparecen individuos de culebra viperina y, más raramente, ejemplares de culebra de escalera (Elaphe scalaris).

Entre los mamíferos, además de los asociados a los asentamientos urbanos - rata común (Rattus norvegicus), ratón común (Mus musculus)—, existen abundantes individuos de musarañita (Suncus etruscus) y de murciélago común (Pipistrellus pipistrellus).

Entre las aves, las más características en esta zona son el papamoscas cerrojilo (Ficedula hypoleuka), el zarcero común (Hippolais polyglota), la lechuza común (Tyto alba) y el torcecuello (Jynx torquilla). Como especies acompañantes y en menor abundancia que las anteriores, aparecen el ruiseñor común (Luscinia megarchynchos), el colirrojo real (Phoenicurus phoenicurus), el mirlo común (Turdus merula), el buitrón (Cisticola juncidis), el gorrión molinero (Passer montanus), etc.

Unidad 3. Esta unidad corresponde a los sectores de laderas y vaguadas en los que se presenta un estrato arbóreo (pinar o encinar) en formación cerrada bajo el cual se desarrolla una vegetación arbustiva y herbácea, por lo general, bien conservada; ello permite el mantenimiento de habitats diversos, sobre los que se asienta una comunidad de especies, fundamentalmente aves, de gran interés científico, cinegético, social y pedagógico.

Merecen destacar por su abundancia: mirlo común (Turdus merula), gavilán (Accipiter nisus), azor (Accipiter gentilis), carbonero garrapinos (Parus ater), herrerillo capuchino (Parus cristatus), reyezuelo listado (Regulus ignicapillus), oropéndola (Oriolus oriolus), chochín (Troglodytes troglodytes), curruca mirlona (Sylvia hortensis), curruca zarcera (S. communis), curruca capirotada S. atricapilla), autillo (Otus scops), etc. 
Entre los mamíferos hay que señalar la presencia, cada vez más escasa, de la gineta común (Genetta genetta); en mayor abundancia, el conejo (Oryctolagus cuniculus) y el ratón de campo (Apodemus syivaticus).

El grupo de los reptiles aún no ha sido abordado en ningún estudio, por lo que no se dispone de datos sobre esta comunidad; no obstante, se pueden señalar como especies propias de este habitat la lagartija colilarga (Psammodromus algirus), la lagartija cenicienta (Psammodromus hispanicus) y la culebra bastarda (Malpolon monspessulanus).

Además de las comunidades citadas, también aparecen diversas especies acompañantes, de las cuales los paseriformes constituyen el grupo más abundante. Entre los fringílidos cabe señalar el piquituerto (Loxia recurvirrostra), verdecillo (Serinus serinus), verderón (Carduelis chloris), lúgano (Carduelis spinus) y pinzón vulgar (Fringilla coelebs).

Entre los páridos, destacan por su abundancia el carbonero común (Parus major), y el mito (Aegithalos caudatus). También son frecuentes algunos colúmbidos paloma torcaz (Columba palumbus), tórtola (Streptopelia turtur), etc.

Unidad 4. Corresponde a los sectores de pinar abierto bajo el cual y entre los árboles, se presenta un estrago arbustivo poco denso. No obstante y, a diferencia del matorral de la unidad anterior, las especies vegetales que habitan estos sectores más soleados presentan, en los meses de primavera, abundantes y vistosas inflorescencias, atrayendo a un gran número de insectos que viven asociados a estas plantas.

Respecto al grupo de vertebrados, esta unidad constituye un estadío de regresión de la unidad anterior, manteniendo únicamente aquellas especies que son menos estrictas en cuanto a requerimientos de habitat y de alimento.

La mayor abundancia la presentan las aves, esencialmente paseriformes: jilguero (Carduelis carduelis), alcaudón común (Lanius senator), curruca tomillera (Sylvia borin), curruca rabilarga (S. undata), alzacola (Cercotrichas galactotes), etc. También se pueden observar individuos de coraciformes, entre los que destacan la abubilla (Upupa epops) y el abejaruco común (Merops apiaster). 
En cuanto a las especies acompañantes, éstas son las mismas que las que se indicaron en la unidad anterior, tanto de aves como de mamíferos y reptiles, si bien en estos sectores suelen aparecer más esporádicamente que aquellos.

Unidad 5. Corresponde a los sectores de roquedo y zonas de monte con un estrato vegetal muy escaso. Este biotipo determina la aparición de especies muy características que se encuentran adaptadas a las condiciones del terreno, como es el caso, entre las aves, del mirlo capiblanco (Turdus torquatus) y el roquero solitario(Monticola solitarius).

Asociada a este medio se encuentra una importante comunidad de reptiles, de la que los más claros representantes son el lagarto común (Lacerta lepida), la lagartija ibérica (Podarcis hispanica) y la culebra bastarda (Malpolon monspessulanus).

Unidad 6. En esta última unidad se recoge una serie de especies características de zonas áridas con un determinado carácter estepario como son el alcaraván (Burhinus oedicnemus), la alondra común (Alauda arvensis), el triguero (Emberiza calandra), la collalba rubia (Oenanthe hispanica), la curruca tomillera (Sylvia conspicillata), la cojugada montesina (Galerida theklae), etc.

- Tema USOS DEL SUELO. Las unidades resultantes para este tema aparecen representadas en el Mapa 8. La simple visualización del mapa permite detectar el cambio sustancial que está teniendo lugar en la zona, principalmente en el sector de la huerta, y al cual ya se han referido numerosos autores (SEMPERE y ZAPATA, 1978; SANCHEZ SANCHEZ, 1980; E.P.Y.P.S.A., 1981; AZARBE, 1982; CALVO GARCIA-TORNEL, 1982). Este cambio tiene su origen en un crecimiento desordenado de la población con la aparición de numerosas viviendas y construcciones, que no responde a ningún plan de conservación del suelo agrícola, ni tan siquiera a una mínima planificación de los sectores habitados. La pérdida de este suelo, de elevada productividad gracias al esfuerzo continuado del hombre a lo largo de los años, resulta verdaderamente paradójica cuando en otros sectores próximos a la vega está realizando la puesta en cultivo de suelos pobres, de escasa o nula productividad, con un gasto considerable de medios técnicos y humanos.

De forma esquemática, las unidades que se han obtenido para este tema son las siguientes: 
Unidad 1. Corresponde a los sectores de cultivos arbóreos, agrios y frutales, que se localizan en el sector de la vega.

La Unidad 2 engloba a las plantaciones de herbáceas que aparecen dispersas por la huerta.

Unidad 3. Corresponde a las zonas de agrios dispuestos en bancales que se presentan en la laderas de los relieves que circundan la vega.

Unidad 4. En esta unidad se recogen los sectores donde aparecen asociadas las plantaciones arbóreas y herbáceas.

Unidad 5. Corresponde a las áreas forestales que se extienden por toda la cadena montañosa de la Cresta del Gallo y, en núcleos más reducidos, algunos cabezos del sector norte. Dentro de la cordillera sur, se incluye parte del Monte El Valle, declarado Parque Natural en septiembre de 1979 (Real Decreto 2611/1979, BOE del 7-IX-79), por iniciativa del Ministerio de Agricultura, sin que hasta el momento se haya elaborado un Plan de ordenación integral que establezca las bases de gestión y conservación del mismo.

Las tres unidades siguientes corresponden a los cauces del Segura y del Canal de El Reguerón.

Unidad 6. Corresponde a los sectores donde los vertidos son fundamentalmente de tipo agrícola (fertilizantes, plaguicidas, herbicidas, etc.); esta carga contaminante llega a los cauces fluviales a través de las aguas de avenamiento que resultan de los excedentes de riego.

Unidad 7. Corresponde a los tramos de agua en los que tienen lugar vertidos de compuestos orgánicos. Las fuentes de estos vertidos suelen ser afluentes domésticos e industriales, y sus efectos más directos son los malos olores y colores del agua por la acción de las bacterias anaerobias que descomponen la materia orgánica, además de interferir en la vida de los organismos y vegetales que se encuentran en estos medios. No obstante, la principal amenaza la constituyen los vertidos orgánicos que proceden de las instituciones sanitarias, como es el caso de la Ciudad Sanitaria «Virgen de la Arrixaca», situada en El Palmar.

Unidad 8. Corresponde al río Segura y al tramo final del Canal de 
El Reguerón en los que tienen lugar vertidos de los dos tipos, agrícola y orgánico. Estas zonas resultan bastante críticas dado que coinciden con los sectores donde el caudal de agua resulta insuficiente para que se produzca una autodepuración biológica de las aguas.

Las dos unidades siguientes corresponden a las zonas que no reciben un uso específico, diferenciándose los cauces de ramblas y cursos esporádicos que se localizan en el sector norte (Unidad 9), de las zonas de eriales y suelos degradados que aparecen dispersos por toda el área de estudio (Unidad 10).

Unidad 11. Esta unidad se localiza en dos zonas de extensión reducida que son dedicadas a la extracción de rocas industriales para construcción y áridos. La primera zona corresponde al sector de Las Canteras, situado en la vertiente NW de la Cresta del Gailo. Hasta hace pocos años, esta zona era utilizada para la extración de cal. Hoy día, una parte de las canteras se encuentra abandonada, dedicándose la otra a la explotación de yesos.

En cuanto a la otra zona, que se localiza en las proximidades de La Cueva, la explotación ha sido muy intensa hasta hace poco tiempo en que, por protestas de los vecinos, se ha deterido toda la actividad.

Unidad 12. Esta unidad corresponde a los espacios de recreo del Valle Perdido y del Valle de S. Juan, que se localizan en la parte baja de la vertiente NW de la Cresta del Gallo, en las proximidades de La Alberca.

La escasez de espacios de este tipo dentro del área de estudio queda suficientemente manifiesta observando la concentración de usuarios que se da en estos sectores en los días festivos.

- Tema PAISAJE. Atendiendo a los rasgos físicos del territorio y a la disposición de los distintos tipos de cultivos y de los asentamientos humanos, se han caracterizado 19 unidades de paisaje. Estas unidades aparecen en el Mapa 9, y son las siguientes:

Unidad 1. Corresponde a las zonas de huerta donde predominan los cultivos arbóreos. La alternancia de las plantaciones de cítricos (naranjos y limoneros) y de rosáceas (melocotoneros, albaricoqueros, manza- 
nos, etc.) lleva consigo un cambio de volúmenes y colores que configuran un paisaje muy peculiar. La visibilidad de esta unidad se encuentra limitada en las áreas inmediatas por el propio estrato arbóreo, aumentando aquélla con la distancia a los cultivos hasta alcanzar su máxima percepción desde los relieves circundantes.

Unidad 2. Corresponde a los sectores de plantaciones herbáceas que constituyen un paisaje abierto respecto a las áreas que los circundan; conforme aumenta la distancia a éstos, la visibilidad disminuye hasta un límite coincidente con un cambio de topografía, a partir del cual aumenta la percepción visual hasta alcanzar su cota máxima en los relieves de mayor altitud. Por otra parte, la naturaleza cambiante de estos cultivos da un carácter dinámico al paisaje agrícola, indicativo de las condiciones socioeconómicas y ambientales que determinan la estructura estacional de las plantaciones.

Unidad 3. En esta unidad se recogen las zonas de cultivos mixtos en los que el arbolado se presenta asociado a las hortalizas ya sea dentro de la misma parcela o en las superficies adyacentes, delimitando aquélla. Manteniendo el carácter paisajístico de las unidades anteriores en estos sectores, la percepción visual viene determinada por la densidad del estrato arbóreo, siendo máxima en la propia plantación y disminuyendo con la distancia a ésta, para aumentar en los relieves que circundan la huerta siempre y cuando los estratos arbóreo y herbáceo no se encuentren yuxtrapuestos.

Unidad 4. Localizada en las laderas y piedemonte de las alineaciones montañosas, esta unidad corresponde a los cultivos en bancales que, como se ha señalado anteriormente, presentan un trazo peculiar, acorde con las características del relieve. La visibilidad de esta unidad se hace mínima en el propio cultivo, aumentando gradualmente con la distancia hasta alcanzar una cota máxima, que viene determinada por un cambio de nivel, a partir de la cual se hace constante.

Unidad 5. Corresponde a las zonas sin vegetación (eriales, suelos degradados, etc.) que, en general, ocupan una superficie muy reducida siendo muy baja su visibilidad, salvo en los puntos más elevados del territorio.

Unidad 6. Esta unidad se localiza esencialmente en la Sierra de la 
Cresta del Gallo y, en menor extensión, en algunas de las alineaciones del sector norte. Está constituída por una vegetación densa de pinar y matorral relativamente bien conservado que, a la escala del ámbito territorial estudiado, representa una calidad visual elevada.

Cuando las condiciones climáticas son favorables (ausencia de inversión térmica, escasa nubosidad), la visibilidad de esta unidad es alta desde la práctica totalidad del territorio, alcanzando los valores más bajos en los sectores comprendidos en la propia unidad.

Unidad 7. Corresponde a las zonas de pinar abierto con individuos de porte arbóreo poco robusto, dejando visible una vegetación arbustiva y subarbustiva rala y poco densa. La visibilidad disminuye conforme aumenta la distancia a la unidad, llegando a confundirse con la unidad anterior en algunos puntos de la Sierra donde se localiza.

En el sector norte, únicamente aparece en la cabecera de algunas de las ramblas que discurren por esta zona.

Unidad 8. Corresponde a los sectores rocosos que presentan una vegetación muy reducida constituída por rupícolas y cuya visibilidad, al tratarse de zonas topográficamente elevadas es, en general, muy alta desde cualquier punto del territorio.

Unidad 9. Esta unidad recoge los sectores de ramblas y vaguadas de la Cresta del Gallo que, por su localización geográfica, presentan una visibilidad escasa dentro de la zona de estudio (excepto en los tramos de cabecera), si bien a escala puntual se clasifican como valles semiabiertos, con una vegetación rala y sustrato rocoso con cantos subangulosos a redondeados, en los que la percepción visual es mayor.

Unidad 10. Localizada únicamente en el Barranco del Sordo, esta unidad está constituída por un valle encajado con fuertes desniveles, sobre todo en los tramos medio y alto, y con un sustrato rocoso en el que se presentan restos de un bosque de galería con una densidad de vegetación elevada que da un marcado constraste al paisaje de todo este sector montañoso. La visibilidad es escasa a escala territorial, e incluso a escala puntual para algunos tramos, siendo mayor la percepción de esta unidad en las zonas más elevadas, próximas a la cabecera. 
Unidad 11. Corresponde a dos sectores aislados de superficie muy reducida, que se localiza en la parte oeste de la vertiente norte de la Sierra; en ellos aparecen restos de un antiguo encinar, en un estado de conservación relativamente elevado que, si bien presentan una escasa visibilidad, constituyen unos sistemas de enorme interés en el campo de la percepción ambiental por ser los únicos vestigios dentro de la zona de estudio de lo que debía de ser el paisaje original en estos montes.

Unidad 12. Esta entidad corresponde a los cursos de agua del Segura y del Canal de El Reguerón. Las características morfoestructurales, edáficas, topográficas y bioclimáticas de estos cauces, y la dinámica de funcionamiento tan peculiar que presentan (cursos divagantes, aumento rápido del caudal, etc.), confieren a estos sistemas unos rasgos de unidad paisajística propia y distinta a las demás, siendo a la vez los principales determinantes de aquéllas.

Unidad 13. Corresponde a dos zonas de canteras, una localizada en Sierra de la Cresta del Gallo, en el sector que recibe el mismo nombre, y otra en las proximidades de La Cueva, que constituyen las principales industrias extractivas dentro del ámbito estudiado.

Estas zonas presentan una visibilidad variable según los puntos del territorio que se consideren, siendo por lo general baja, dada la superficie tan reducida que ocupan.

No obstante, teniendo en cuenta el impacto que a nivel paisajístico produce este tipo de actividades y a las nuevas normativas legales surgidas al respecto (Real Decreto 2994/1982 de 15-X-1982), se ha considerado conveniente diferenciar estas zonas como una unidad propia.

Unidad 14. en esta unidad se recogen aquellos sectores de montaña en los que, debido a su localización geográfica y a las condiciones de topografía elevada que presentan, la visibilidad resulta escasa o nula respecto a los demás puntos del territorio. La percepción visual desde esta unidad también se encuentra muy reducida.

La diferenciación de estos sectores resulta de enorme interés a efectos de localización de usos, cuando se trata de un territorio de dimensiones reducidas como el que se considera en este estudio. 
Unidad 15. Esta unidad recoge áreas muy puntuales donde se localizan los aparatos tradicionales de elevación de aguas, que han jugado un papel elemental en la configuración del paisaje agrario.

De la totalidad de aparatos elevadores que funcionaban en la huerta de Murcia en los siglos XVIII y XIX (más de un centenar) hoy sólo queda una porción ínfima, distinguiéndose tres tipos (MONTANER SALAS, 1982): la noria, de la que existen dos ejemplares en la zona de estudio; el arte, que aparece en tres sectores, y el ceñil, del que se encuentran varios artefactos repartidos por el área de la huerta, si bien, en un número sensiblemente inferior al que presentaban anteriormente. En cuanto a las aceñas, tan abundantes en épocas pasadas, éstas han desaparecido en su práctica totalidad, no observándose ninguna dentro de la zona considerada en este estudio.

Las cuatro unidades últimas corresponden a los distintos asentamientos urbanos e industriales que se localizan en el área de Murcia; si bien estos sectores no han sido considerados en las fases posteriores de diagnóstico y evaluación de impactos, sí se ha creído conveniente apuntarlos en el tema de paisaje, dado que constituyen un factor clave en el proceso de cambio que, desde fechas recientes, está teniendo lugar en la zona. Así pues, atendiendo al tipo de asentamiento, a la densidad de población, y al carácter de las viviendas, se han diferenciado los siguientes sectores o unidades:

Unidad 16. Corresponde a la ciudad de Murcia. Este núcleo, con una densidad de población elevada, presenta una estructura (edificios de 5 o más plantas, amplias avenidas y plazas, etc.) y una dinámica de funcionamiento (entrada y salida de materia, flujo de energía) muy peculiares, características de los sistemas hipoenergéticos a que alude Mori en su estudio (MORI, 1977).

Unidad 17. Corresponde a los núcleos pedáneos que circundan la vega y algunos otros que aparecen dispersos por ésta. Estos sectores se caracterizan por unas densidades de población bajas (inferior a 1000 $\mathrm{hab} / \mathrm{km}^{2}$ ), y en los que aún se presentan los asentamientos de tipo tradicional (edificios de una a tres plantas y pequeñas áreas de cultivo próximas a las viviendas), manteniéndose un sistema de relaciones urbanorurales más o menos equilibrado, si bien, éste resulta bastante precario teniendo en cuenta la crisis comercial de algunos de los productos de la 
huerta. Se puede considerar como un paisaje energéticamente en equilibrio (MORI, 1977).

Unidad 18. En esta unidad se recogen los asentamientos de tipo industrial que aparecen dispersos por la huerta, normalmente próximos a las redes viarias, y más concentrados en el sector norte, donde alcanzan una extensión mayor.

En general, los que ocupan el sector de vega no constituyen un impacto elevado ya que, por su emplazamiento entre los cultivos, presentan una escasa visibilidad; por otra parte, al tratarse en su mayoría de naves de almacenamiento y de mataderos que no producen vertidos de humos o aguas residuales, la intercepción con la unidades adyacentes tampoco reviste mayor importancia, a excepción de los sectores próximos al pie de monte de la Cresta del Gallo, donde sí se producen algunas emisiones a la atmósfera que, en situación de inversión térmica, disminuyen considerablemente la visibilidad.

Unidad 19. Corresponde a los asentamientos residenciales que aparecen diseminados en forma de viviendas aisladas por todo el sector de la Cresta del Gallo, abarcando una mayor extensión en la parte NW de la sierra, donde constituyen núcleos urbanos de carácter residencial. El tipo de construcción en estos sectores consiste en edificios de una o dos plantas, y con espacios verdes que separan unas viviendas de otras; estas zonas verdes suelen estar ocupadas por plantas de jardín, si bien en algunos casos suelen ser aprovechadas para la implantación de cultivos de diversa indole, disponiendo así de un pequeño huerto familiar.

La visibilidad de estos núcleos dentro del ámbito estudiado suele ser escasa o nula, exceptuando los sectores próximos a ellos en donde el impacto visual es muy elevado.

\section{DISCUSION}

En primer lugar, hay que hacer notar la ausencia de estudios temáticos actualizados y a escalas de trabajo adecuadas. De ahí que la labor de prospección y sectorización del territorio comprendido en este estudio haya resultado simplificada para algunos de los temas considerados (por ejemplo, Suelos y Fauna). Son necesarios, por otra parte, unos estudios 
detallados dirigidos a la realización de una cartografía temática completa sobre esta zona de indudable interés económico y social para la región, e incluso más allá de estos límites.

Esta necesidad se hace aún más imperiosa en el sector de la vega, en donde la activa expansión urbanística está llevando a este núcleo eminentemente agrícola a su total desaparición si no se establecen unas normas claras y precisas sobre las actuaciones que se han de seguir a corto, medio y largo plazo. Un exponente claro de este problema lo constituye la ciudad de Murcia, localizada sobre un suelo eminentemente agrícola, y donde existen serios problemas relacionados con el microlina y el relieve (frecuencia de inversión térmica, riesgos de inundación, etc.); ello hace del todo inadecuada su situación en este sector, y más aún su expansión a lo largo del eje del Segura.

Diversos autores han expuesto la situación en que se encuentra la huerta (SEMPERE y ZAPATA, 1978; CALVO GARCIA-TORNEL, 1982; AZARBE, 1982). La situación llega a ser preocupante cuando se observa que casi el $10 \%$ de la superficie de vega estudiada está ocupada por edificaciones, sin incluir los núcleos pedáneos, viales, acequias, etc.

Por otra parte, el proceso de expansión urbana a costa de la huerta circundante lleva consigo la creación de servicios anejos (establecimientos sanitarios, comerciales, redes viarias, etc.) y la alteración de aquéllos que eran necesarios para la agricultura tales como la red de riegos, que ha quedado parcialmente cubierta por el crecimiento de la ciudad. Ello plantea serios problemas, entre los cuales la limpieza de los cauces es de los más acuciantes.

Asimismo, esta tendencia a transformar en zona urbanizable un sector eminentemente agrícola lleva consigo un aumento del valor del suelo, lo que resulta contradictorio en relación a la renta que genera (desde el punto de vista agrícola) (SEMPERE y ZAPATA, 1978).

Un problema también acuciante, lo presenta la contaminación creciente de los cursos de agua que discurren por el área de estudio. Las zonas en las que se presenta una contaminación elevada corresponden al Guadalentín (Canal de El Reguerón), en los tramos que discurren desde El Palmar hasta Algezares y desde Beniaján hasta la confluencia con el Segura. Este último presenta una carga contaminante elevada desde su 
entrada en la ciudad de Murcia. No obstante, el caudal que lleva este río, si bien se mínimo en la mayor parte del año, hace que el grado de contaminación sea algo menor que el que se da en el Canal del El Reguerón, en el que la escasez del caudal que lleva a su paso por El Palmar (aguas de vertidos, únicamente) determina unas comunidades de organismos más específicos de condiciones de contaminación orgánica extrema (situaciones de anoxia, altas concentraciones de nutrientes, etc.) (SUAREZ et al., 1983).

En cuanto a las aguas con contaminación moderada, éstas comprenden el tramo del Segura que discurre por la zona de estudio antes de su entrada en la ciudad de Murcia, en el que debido a la capacidad de autodepuración de las aguas, se da una cierta disminución de la carga contaminante que proviene de Molina de Segura.

También en el tramo del Guadalentín que va desde los Garres a Beniaján, en el que se da un aumento del caudal debido a la entrada de aguas de avenamiento que proceden únicamente de los sobrantes de riego de los cultivos que circundan este tramo, el grado de contaminación se vé disminuído.

De los tipos de vertidos - agrícolas y orgánicos- que reciben los cursos de aguas, los primeros, por lo general, no entrañan graves problemas para el hombre cuando las aguas vuelven a ser utilizadas con fines agrícolas, si bien, constituyen una amenaza directa para las comunidades acuáticas que habitan este medio.

En cuanto a los vertidos orgánicos, y como ya se apuntó en el tema Usos del Suelo, los procedentes de las instituciones sanitarias constituyen una seria amenaza. SUAREZ et al., (1983) han expuesto los peligros que presentan este tipo de vertidos a aguas que van a ser utilizadas posteriormente, como es el caso que nos ocupa, y que requieren un tratamiento intenso a fin de eliminar los agentes infecciosos (bacterias, virus) que entrañan un riesgo considerable para el hombre y los demás seres vivos. Existe, pues, una necesidad urgente de impedir los vertidos de aguas residuales a los cauces, sin una depuración previa, así como la existencia de un caudal mínimo de agua en el río Segura que ayude a una autodepuración del mismo. También es esencial una remodelación del paisaje de ribera de estos cauces, con regeneración de la vegetación de borde, plantaciones de setos y restauración de edificaciones que dan al río. 
Un problema no menos trascendente en la zona lo constituyen las inundaciones de las áreas inmediatas a los cursos de agua. Su utilización para la implantación de viviendas e industrias supone un riesgo contínuo frente a las avenidas. Es necesario, pues, evitar la invasión de estos sectores por actividades que conlleven instalaciones e infraestructuras.

Dentro del tema de Vegetación y Cultivos, y refiréndonos a estos últimos, debido a las costumbres, muy extendida en la zona, de localizar varios esquilmos en la misma parcela, resulta difícil calcular con exactitud la superficie atribuible a cada uno de los distintos tipos de cultivo existentes. Por esta razón se han agrupado bajo la denominación de «cultivos mixtos» aquéllos sectores donde los cultivos arbóreos se combinan con los herbáceos, incluso dentro de la misma parcela. Estos cultivos ocupan una extensión apreciable (el $10,57 \%$ ), debido esencialmente al escaso tamaño de las explotaciones. Durante el período de crecimiento de los frutales, éstos no producen ningún benéficio para el agricultor, que necesita obtener algún rendimiento viéndose por ello obligado a realizar cultivos de suelo durante ese tiempo (CALVO GARCIA-TORNEL, 1982).

Comparando los cultivos arbóreos y herbáceos que ocupaban la huerta en 1963 (I.O.A.T.S., 1963) con los actuales, se observa un ligero incremento de los primeros $(12 \%)$ y una disminución de los segundos, respecto a aquél año (aunque en los datos del I.O.A.T.S. no se señalan los cultivos mixtos, considerando éstos junto con los herbáceos, se obtiene un valor del del $30,24 \%$ de superficie en 1982, lo que aún es inferior al valor correspondiente a 1963 , de $36,2 \%$ ).

Hay que tener en cuenta que en este estudio no se ha considerado la totalidad de la huerta de Murcia, habiéndose excluído un sector de la parte $\mathrm{E}$ en el que posiblemente se encuentra una mayor proporción de cultivos herbáceos. No obstante, los datos obtenidos por CALVO GARCIA-TORNEL en 1970, considerando toda la huerta, reflejan ya una disminución del $5 \%$ de la superficie atribuible a los cultivos herbáceos, respecto a 1963. Asimismo, este autor señala una extensión de 13.815,9 ha (el $68,5 \%$ de la superficie total) para las plantaciones arbóreas, lo que indica un incremento notable de estos cultivos respecto $1963(46,3 \%)$ (CALVO GARCIA-TORNEL, 1982).

Respecto al tema de Fauna, la idea inicial de caracterizar las distintas 
unidades en función de los tipos de cultivos que se localizan en el sector de huerta, hubo de ser abandonada por dos razones: la primera está relacionada con la capacidad de dispersión de los diversos grupos taxonómicos, la cual condiciona sensiblemente la caracterización de las unidades faunísticas espaciales. Ello ha requerido un análisis detenido de los distintos taxones que habitan la zona, seleccionando aquéllos que, o bien presentan una mayor conspicuidad, o bien tienen una menor capacidad de dispersión, o ambas cosas. No obstante, en general, la superficie que abarcan en sus desplazamientos es sensiblemente mayor a la que ocupa una unidad de cultivo.

Por otra parte, la ausencia de un «pattern» o modelo de distribución de los cultivos hacen del todo imposible una tipificación de las comunidades animales basada en la naturaleza de las plantaciones que existen en el área estudiada.

Por último, una zona eminentemente conflictiva la costituye la Sierra de la Cresta del Gallo y, más concretamente, el sector comprendido dentro del Parque Natural del Monte El Valle. Dejando a un lado la figura de espacio natural protegido bajo la cual se ha recogido esta zona, resulta un tanto anecdótico que, desde su creación en 1979, no se haya elaborado aún un Plan de Ordenación Integral que contenga las medidas de conservación, preservación y disfrute y las Normas y reglamentos aplicables al Parque Natural del Monte El Valle.

\section{AGRADECIMIENTOS}

Los Dres. Ortiz Silla, del Departamento de Geología, y López Bermúdez, del Departamento de Geografía Física General, de la Universidad de Murcia, han prestado una inestimable ayuda en la prospección y sectorización de los temas de Geología, Suelos y Geomorfología. 


\section{BIBLIOGRAFIA}

ARENAS CUEVAS, M., (1980). Características geomorfológicas de las cuencas y subcuencas del Segura. IGME, Ministerio de Industria. Inédito.

AZARBE, Cooperativa de Proyectos y Estudio, (1982). La singularidad del Municipio de Murcia. Excmo. Ayuntamiento de Murcia. Murcia.

BOLOS, O. de, (1967). Comunidades vegetales en las comarcas próximas al litoral situadas entre los ríos Llobregat y Segura. Mem. R. Acad. Ciencias y Artes, 38(1): 1-270.

CALVO GARCIA-TORNEL, F., (1969). La Huerta de Murcia y las avenidas del Guadalentín. Papeles del Dpto. de Geografía, I: 111-137.

CALVO GARCIA-TORNEL, F., (1971). Aspectos de la ecolución de la propiedad territorial en la huerta de Murcia. Papeles del Dpto. de Geografía. Universidad de Murcia: 135-158.

CALVO GARCIA-TORNEL, F., (1982). Continuidad y cambio en la Huerta de Murcia. Acad. Alfonso X el Sabio, 34. Murcia, 353 p. (2." ed.).

DIAZ-PINEDA, F., GONZALEZ BERNALDEZ, F., NICOLAS, J.P. de, (1979). Descripción automática de la vegetación. III Clasificación y ordenación simultánea de datos cualitativos. Anal. Edaf. y Agrobiol., XXXVIII(11-12): 2207-2224).

EDINGTON, J.M., EDINGTON, M.A., (1977). Ecology and environmental planning. Chapman and Hall, Londres, $246 \mathrm{p}$.

E.P.Y.P.S.A., (1981). Estudio de reconocimiento territorial de Murcia. CEOTMA-Comunidad Autónoma de la Región de Murcia. Murcia.

ESTEVE CHUECA, F., (1972). Vegetación y flora de las regiones Central y Meridional de la provincia de Murcia. C.E.B.A.S. I.O.A.T.S. Murcia, 451 p.

FERNANDEZ GALIANO, E., NOVO, J., (1965). Vegetación natural. En: I.O.T.S. 1966, Op. cit.

GONZALEZ BERNALDEZ, F., MARTIN DE AGAR, P., RODENAS, M., SANCHO ROYO, $\mathrm{F}$., (1974). Un système d'enregistrement et minimisation des impacts sur l'environnement: IRAMS. Colloque International «Informatique et Environnement». Fond. Univ. Belge. Arlon, Bélgica.

I.O.A.T.S., (1983). Estudio edafológico y agrobiológico de la huerta de Murcia. 1.O.A.T.S. Murcia, $183 \mathrm{p}$.

I.O.A.T.S., (1966). Estudio edafológico y agrobiologico de la provincia de Murcia. C.E.B.A.S. I.O.A.T.S. Murcia, 282 p.

LEON, A. de et al., (1974). Caracterización agroclimática de la provincia de Murcia. Ministerio de Agricultura, Madrid, $38 \mathrm{p}$.

LITTON, R.B., (1973). Landscape control points: A procedure for predicting and monitoring visual impacts. USDA Forest Service Res. Paper PSW-91. Berkeley, California. 
LOPEZ BERMUDEZ, F. et at., (1979). Inundaciones catastróficas, precipitaciones torrenciales y erosión en la provincia de Murcia. Papeles del Dpto. de Geografía, 8: 49-91.

MARTIN DE AGAR, M.P., (1983). Ecología y planeamiento territorial: metodología y estudio de casos en la Región Murciana. Tesis Doctoral, Universidad de Murcia, 650 p. (Inédito).

MARTIN DE AGAR, M. P., MEDINA, S., RAMIREZ DIAZ, L., (1982). Incorporación de factores ecológicos y ambientales en la ordenación del territorio. Estudios Territoriales, 6: 157-168.

MARTIN DE AGAR, M.P., RAMIREZ DIAZ, L., (1984). Utilización de archivo de datos en la explotación de la información ambiental. Anal. de Biologia, Universidad de Murcia.

MARTIN DE AGAR, M.P. TORRES MARTINEZ, A., RAMIREZ DIAZ, L., (1984). Ecologia y organización del territorio: el caso de la aglomeración urbana de Murcia y su área de influencia. II: Diagnosis y evaluación de impactos ambientales. (En prensa).

MARTIN DE AGAR, M.P., TORRES MARTINEZ, A., RAMIREZ DIAZ, L., (1984). Ecología y organización del territorio: el caso del Mar Menor y ecosistemas adyacentes. (En prensa).

MONTANER SALAS, E., (1982). Norias, aceñas, artes y ceñiles en las vegas murcianas del Segura y Campo de Cartagena. Biblioteca Básica Murciana, 4. Ed. Regional de Murcia. Murcia, $117 \mathrm{p}$.

MONTURIOL, F. et al., (1978). Cartografía edafologica y capacidad de uso de los suelos de la franja costera de la provincia de Santander. CIDS, Santander.

MORI, A., (1977). Classification et cartographie du paysage sur base écologique avec aplication á l'Italie. Geoforum, 8(5-6): 327-340.

RODENAS LARIO, M., (1977). Planificación urbanistico-ecológica: problemática de tratamiento de datos y sectorización. Tesis Doctoral, Universidad de Sevilla. (Inédita).

SANCHEZ SANCHEZ, J., (1980). La Vega Media. En: Varios Autores Historia de la Región Murciana, Ed. Mediterráneo, S.A. Murcia.

SANCHO ROYO, F., FERNANDEZ ALES, R., GONZALEZ BERNALDEZ, F., RODENAS LARIO, M., (1981). Sistema IRAMS: Evaluación de alternativas de uso en la ordenación integral del territorio. Serv. Publ. Universidad de Sevilla. Sevilla, $102 \mathrm{p}$.

SAURA, F., FERRERAS, C., (1976). Estudio climatologico de la provincia de Murcia. I.O.A.T.S. Murcia, $120 \mathrm{p}$.

SEMPERE, A., ZAPATA, M., (1978). La huerta de Murcia al desnudo. Estudio sociológico comarcal. Acad. Alfonso X el Sabio. Murcia, $182 \mathrm{p}$.

STEINITZ, C., (1979). Simulating alternative policies for implementing the Massachussets scenic and recreational rivers act: The north river demonstration project. Landscape Plann., 6: 51-89.

SUAREZ, M.L. et al., (1983). La calidad de las aguas del canal de desagüe de «El Reguerón» (río Guadalentín: cuenca del Segura). Ann. Univ. Murcia (Ciencias) XLII (1-4): 201-236. 
VARIOS AUTORES, (1983). Diagnosis biológica de las aguas del curso medio del río Segura (Murcia). Univ. Murcia-Comunidad Autónoma de la Región de Murcia. Murcia. (Inédito).

WEDDLE, A.E., (1969). Landscape with figures. The Town Planning Rev., 39(4): 307-318.

ZUBBE, E.H. et al., (1974). Perception and measurements of scenic resources in the Southern Connecticut River Valley. Inst. for Man his Environnment, Publ. R-74-1. Univ. Massachussetts, Amherst. Massachussetts. 
Sector do piedemonte de la Alberca.Ta máx, y mín.

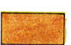

1 Ser \{\}$:$ is

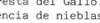
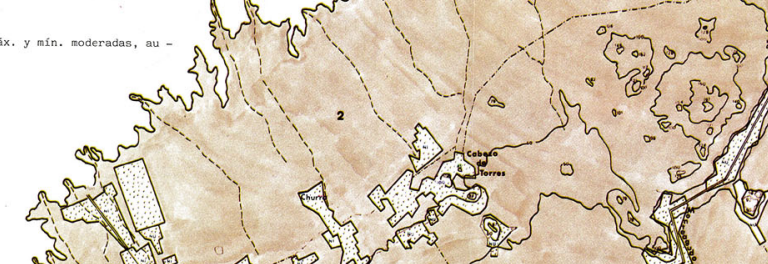

$y_{0}$ की

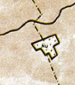
shng ?
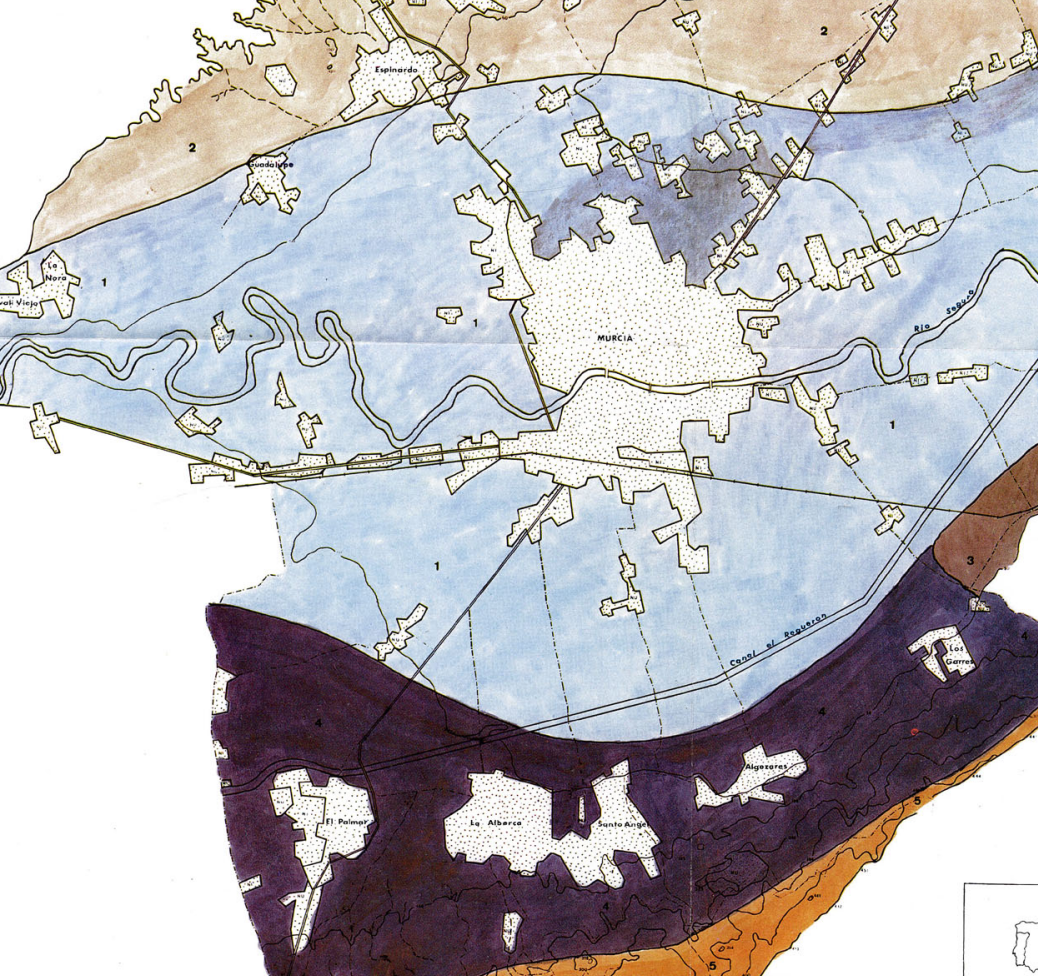


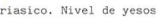

Cuaternario, Terraza anferior
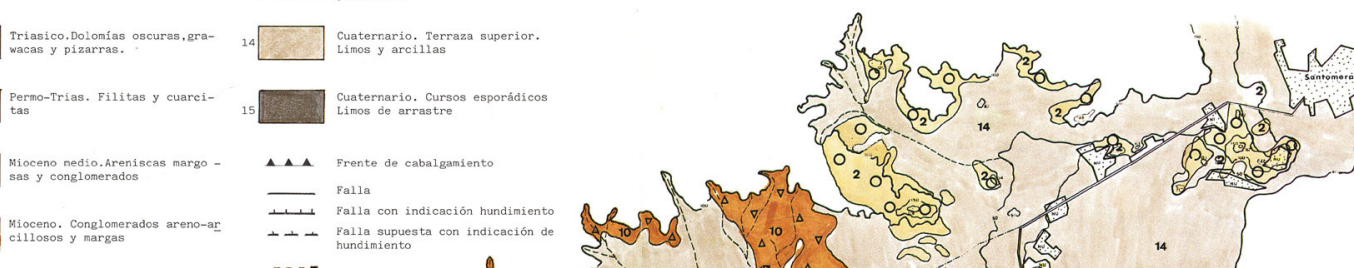

\begin{tabular}{l} 
14. Frente de cabalgamiento \\
+ Falla \\
\hline L Falla con indicación hundimiento
\end{tabular}

LL Falla con indicación hundimiento
-+- Falla supuesta con indicación de

Mioceno medio-superior. Conglomerado
de cantos dolomíticos y eqquistos me팜 som $x$

Hoceno superior. Margas y areniscas

Mioceno superior. Margas y ar
con abundancia de carbonatos
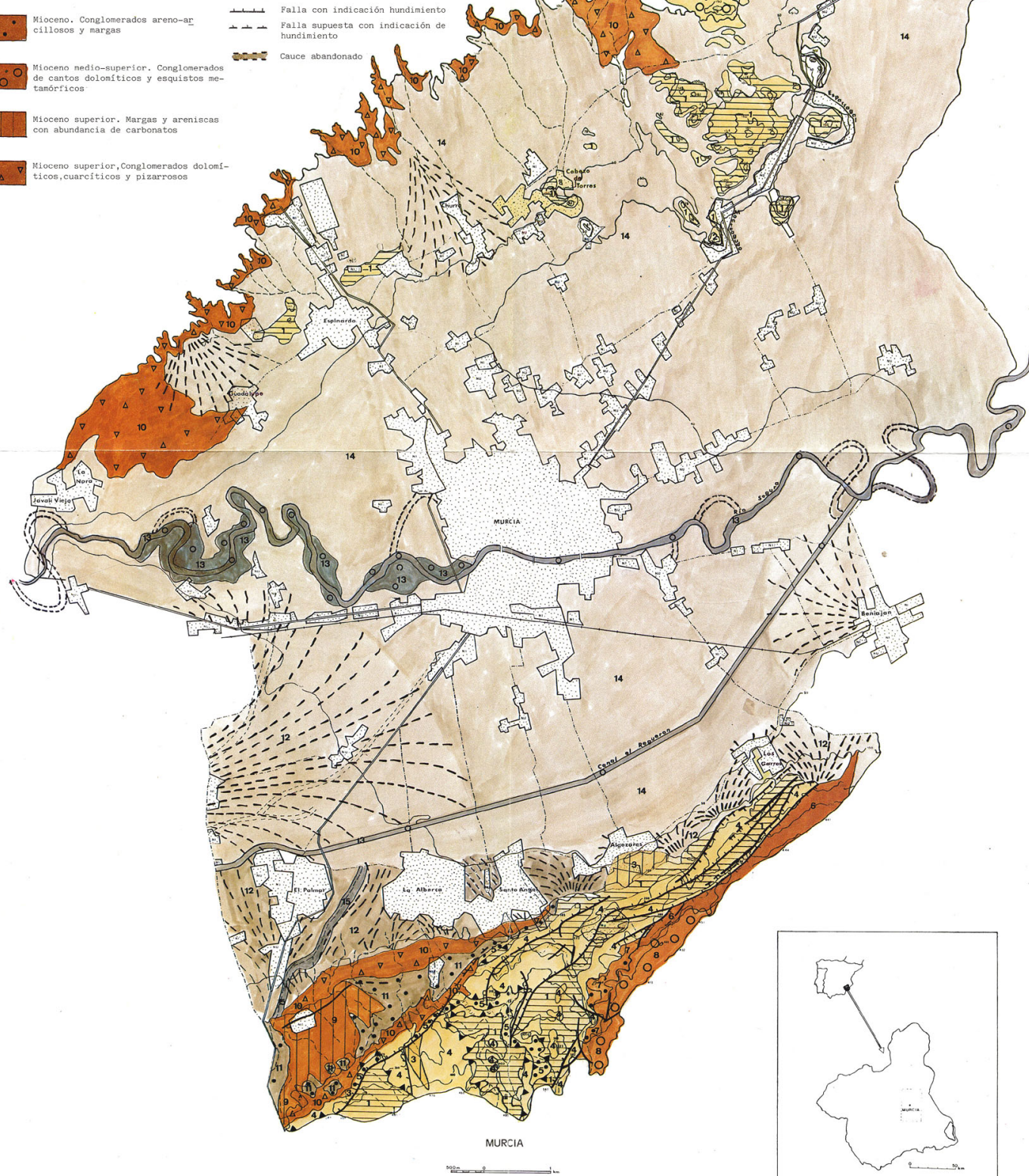


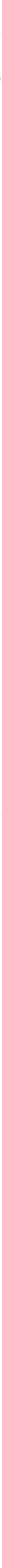



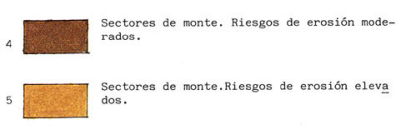

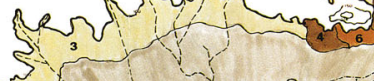
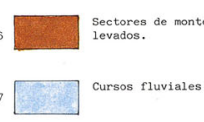

\section{as}
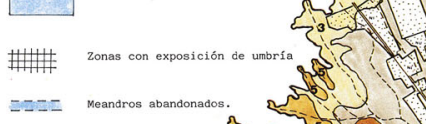
zns?

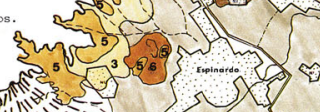

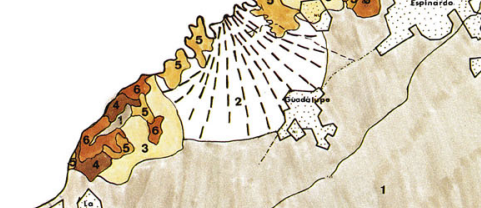

5 .

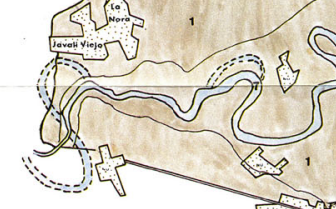




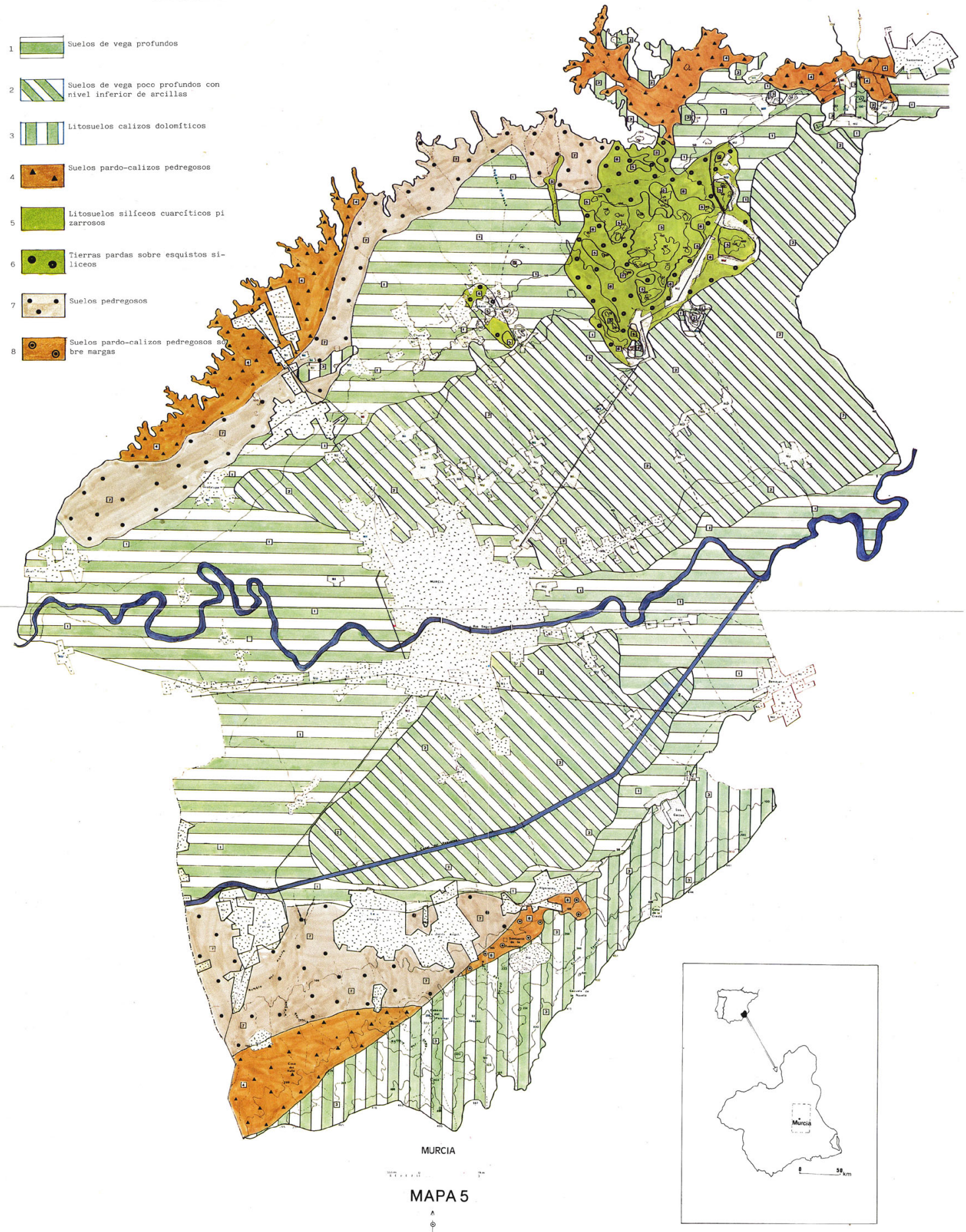




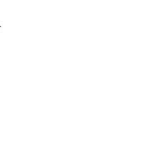

\begin{tabular}{l|l|l} 
Plantaciones mixtes de aerios y \\
\hline
\end{tabular}

$5 \square\left[\begin{array}{l|l|l}\text { Oytivos de agrios en suelos de } \\ \text { vega }\end{array}\right.$

6 $\because \ldots$ Plantaciones de frutales cur hue

Sectores mixtos de frutales y

herbáceas
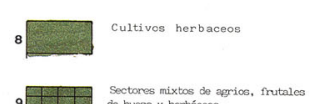

${ }_{10 \square}^{10}$

de tueso $y$ herbáceas
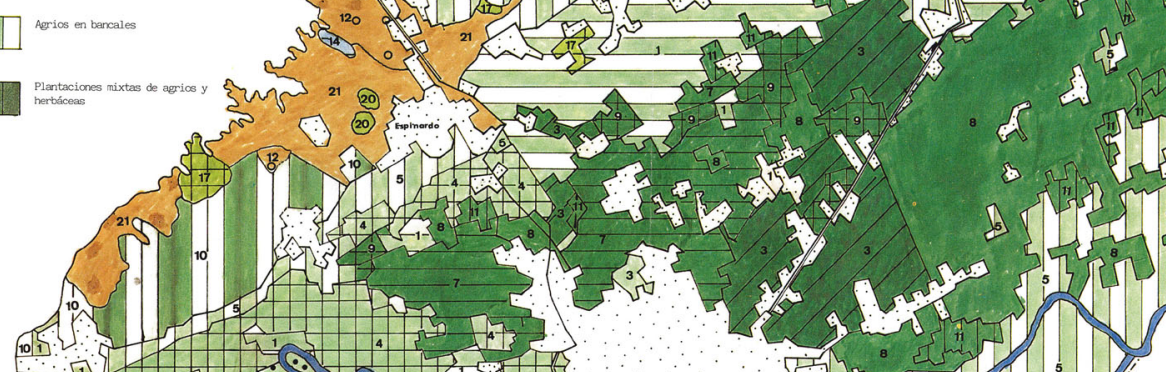

herbícteas

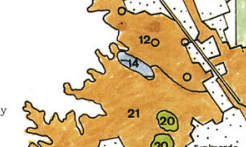

$\left\{\begin{array}{c}3 \\ 3\end{array}\right\}$

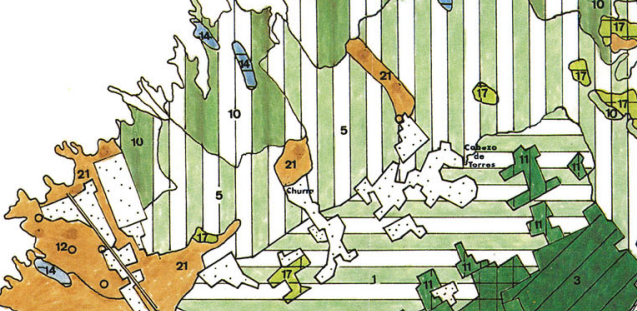

ere
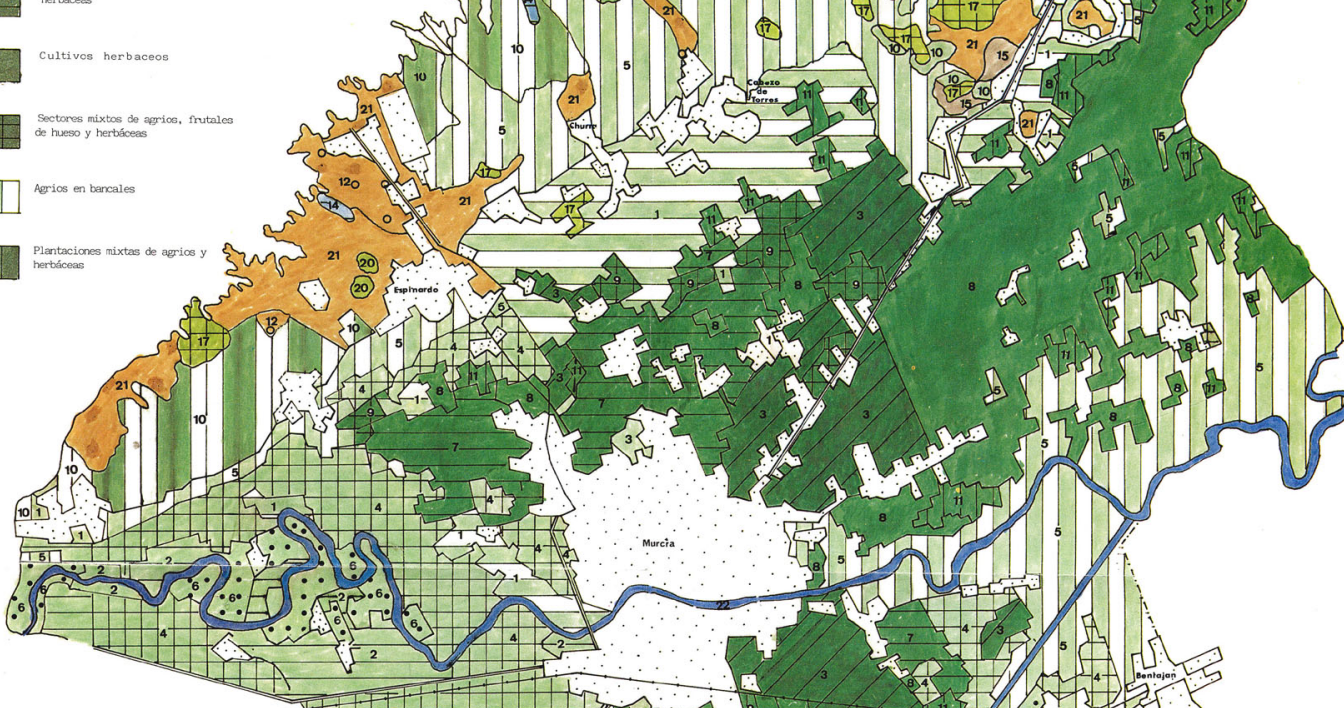

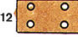

Cultivos artrénes de secano

Ramblas y Vagndes. Bosque
de galería

Rambles $y^{\prime}$ Yagyarlas degrach

das. Fredonisio de nitrófi-

Vegetación rupíalla

Bosque de "pino carrasco" (P. Halepensis) cn formecion abiet ta, con matorral des g

Bosque de"pino car

rral gipsícola

de vegetación arbustiva

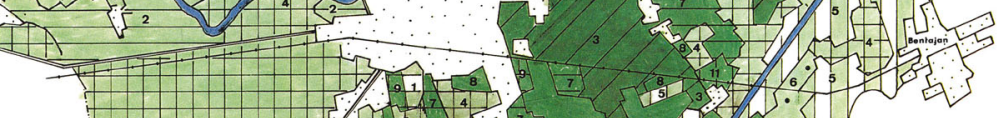

5 5 $1 \sqrt{3} \quad 4 \quad \& 4$
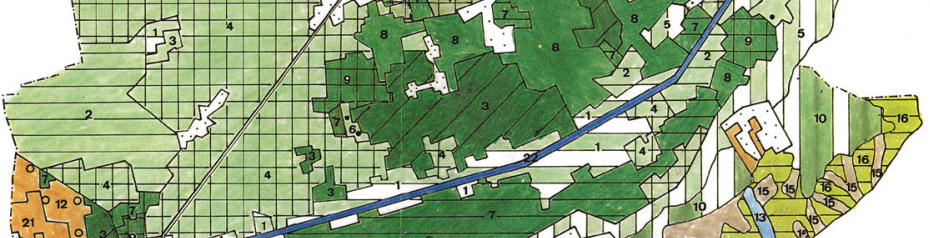

(12)

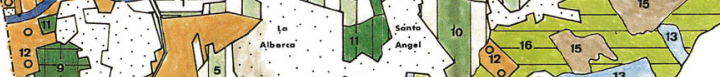

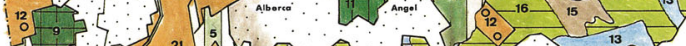

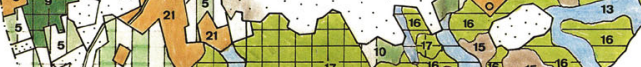

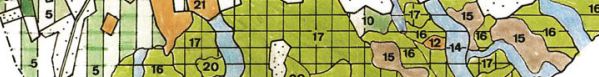

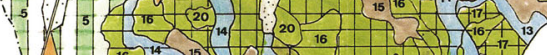
(2)

a. (3).

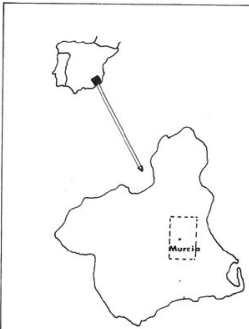

Erieles 


\section{[IIII}

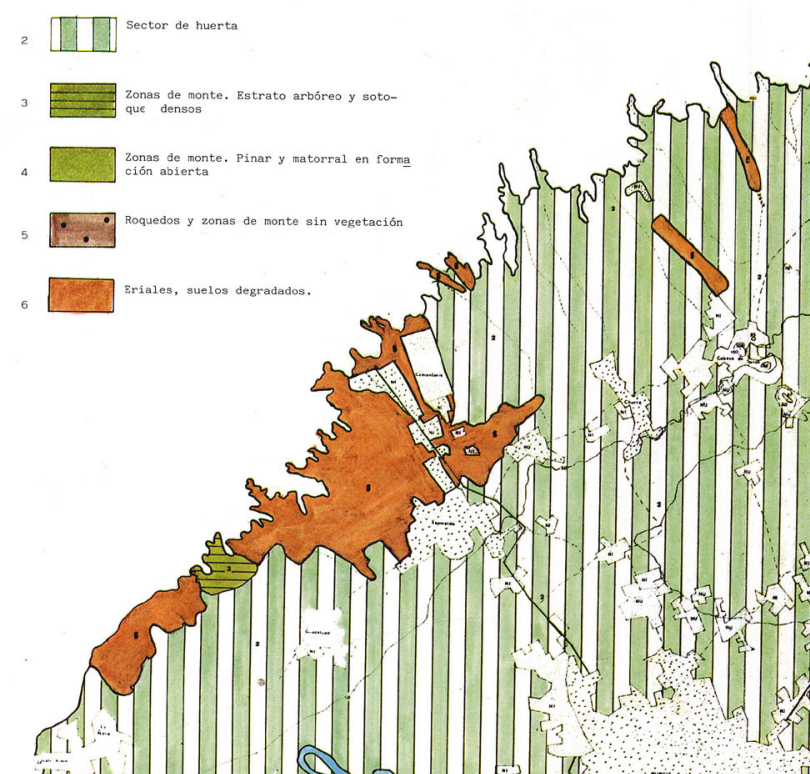

Zonas de monte.
que densos

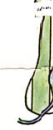

Intera

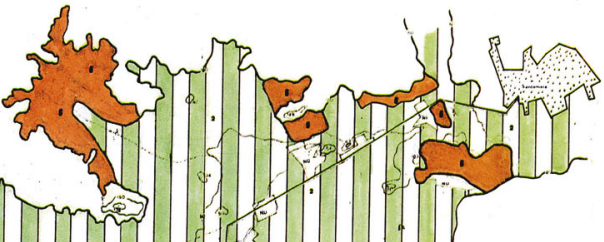

Zonas de mon
ción abierta

(

. 


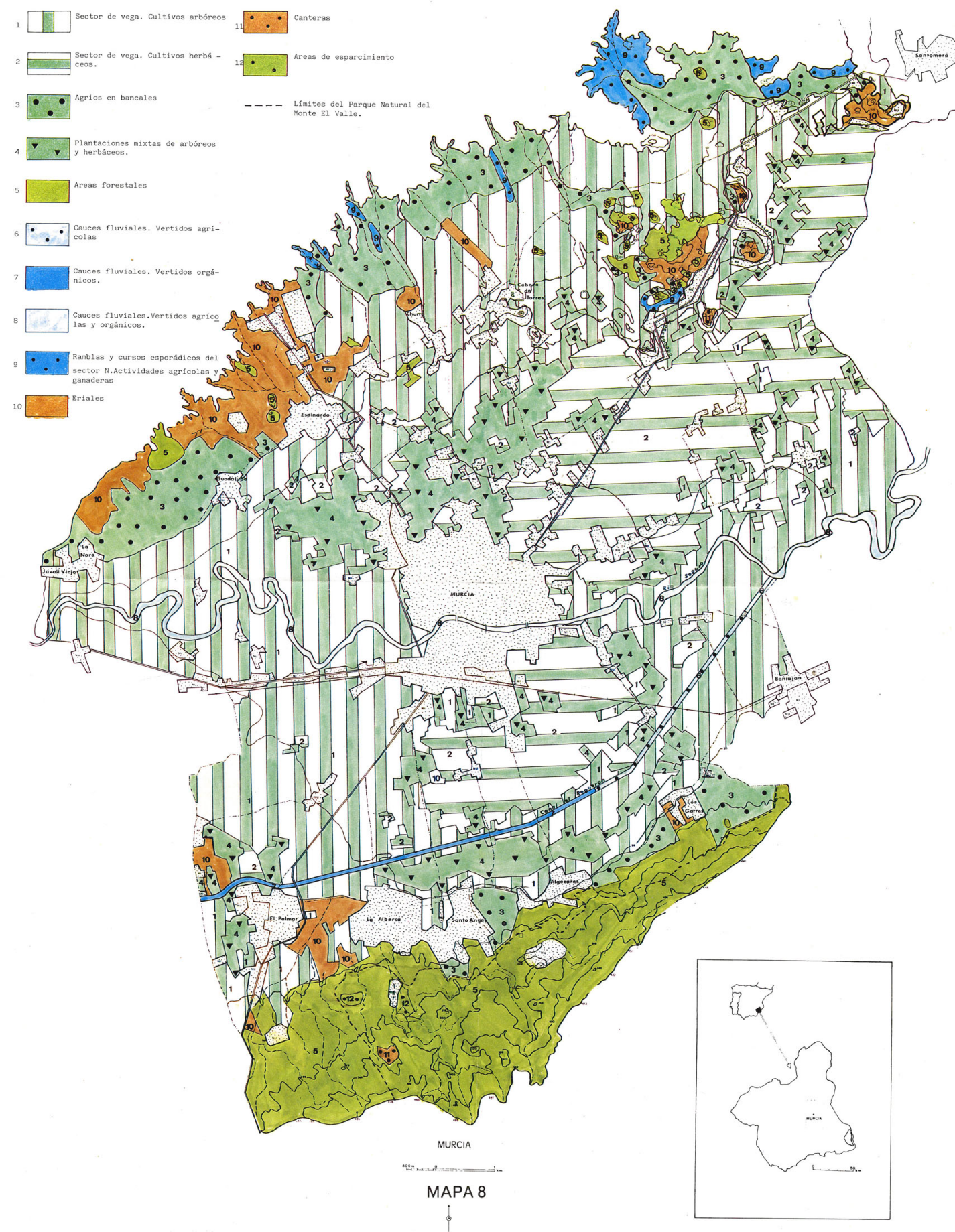


